\title{
Why do nurse graduates choose to work in the area of mental health?
}

\author{
by
}

Anna Kempthorne

A thesis submitted to the Victoria University of Wellington

in partial fulfilment of the

requirements for the degree of

Master of Arts (Applied)

in Nursing

Victoria University of Wellington

2006 


\section{Abstract}

The low numbers of nurses attracted to work in mental health is a concern particularly with the increased demand for mental health services. Strategies are required to increase recruitment to this less popular area of nursing to ensure that a high quality of care is provided for people suffering from mental illness. The World Health Organisation (2004) is aware that this area of health has been neglected and that it is time to promote mental health. This study aimed to examine the influences involved in nurses choosing to work in this area.

A descriptive survey using a questionnaire was given to seven groups of new graduates enrolled in the New Graduate Mental Health Nursing programme through five educational institutes within New Zealand. At the time of writing there were no published studies around this topic in New Zealand. This study will attempt to inform nurses, the Nursing Council of New Zealand, tertiary institutions and the government of New Zealand that there is evidence that we need to develop and change practices to address the predicted workforce decline. 


\section{Acknowledgements}

In order for me to have achieved completion of my research project there were many people involved in my journey and I would like to thank them for their direct and indirect support on the way.

To the Victoria University of Wellington Human Ethics Committee for approving this research project

To Brenda Happell for allowing me to use the questionnaire that she developed in her study.

To Brian Phillips, supervisor, for keeping me focused and motivated.

To my employer, CCDHB for supporting me financially for this thesis paper

To the lecturers, Stuart McDonald, Duncan Milne, Jacquie Kidd, Rebecca Hennephof, Jenny Nichols, Gail Houston, and Carmel Haggerty who supported me by giving out questionnaires in class time and to the students that have agreed to participate in the survey

To my colleagues that agreed to participate in the pilot study

To Rita McEwan who has provided the scholarships that I have benefited from for my two years leading up to this thesis

To my family who have supported me to complete my studies and have given up time on the computer so I could use it 


\section{Table of Contents}

\section{Page}

Chapter 1. Introduction............................6

Chapter 2. Literature Review.......................9

Chapter 3. Research Design.......................24

Chapter 4. Results..................................39

Chapter 5. Discussion..............................55

Chapter 6. Conclusion...............................72

References........................................76

Appendix.........................................80 


\section{List of Tables/Graphs}

Table 1. Number of Ethnic groups identified by participants....44

Graph 1. Age/Sex distribution .................................43

Graph 2. Nursing career preferences...........................46

Graph 3. The relative popularity of nursing career choices......47

Table 2. Reasons given for the most preferred option............49

i. Professional development..............................49

ii. Self-satisfaction........................................49

iii. Specific skills.......................................50

iv. Personal needs......................................51

v. Comparison to general nursing........................51 


\section{Chapter One}

\section{Introduction}

As a Clinical Nurse Specialist in a rehabilitation unit in mental health, I frequently feel frustration with the on-going problem of poor nurse numbers that are attracted to this area of nursing. I am proud to work in this area of nursing but I continue to recognise the stigma that is associated with mental illness through family, friends and the general community. I realise that the problem of recruitment and retention exists throughout all areas of nursing, and throughout the world. I would like to devise some strategies that will attract nurses to the particular area I work in at present using the information that I obtain through this research.

The Clinical Training Agency (CTA) is a business unit established through the Ministry of Health of New Zealand and is responsible for funding post-entry clinical training in the health and disability sector. This was established in an attempt to support nurses' transition in their first year of practice and provide a consistent standard of nursing care. By aiming for this consistency, there may be some issues addressed around recruitment and retention of staff in all areas of health. The CTA works with the sector to identify training needs, consults with key groups to develop training specifications, funds providers to deliver that training, and monitors their performance in response to workforce development needs. The unit provides the incentives for nurses to work in specific areas of nursing through a fully funded programme with opportunity to work in specific areas. This is the reason I have chosen to survey a group of postgraduate nurses who have enrolled in the CTA course for new graduates to mental health nursing.

In the role of Clinical Nurse Specialist, I orientate undergraduate nurses during their mental health placement and ensure their three to four week placement covers the objectives of their course. I have devised an evaluation form at the end of their placement to allow feedback to ensure future student placements fulfil the needs and desires of the students. This has allowed valuable information to be collected on how to improve each 
placement for the student nurses. This has also provided me with some ideas about what makes nurses enjoy mental health.

It was during an orientation to a group of newly registered nurses that one of these nurses exclaimed that it was the placement in our unit that made her want to return to mental health. This exciting reaction made me want to explore further. I wanted to know if other nurses in a similar situation had evaluated their mental health undergraduate placement in a comparable fashion and this had encouraged them to return to the area of mental health once they had graduated. There is a shortage of nurses not only in rehabilitation but all areas of mental health. This area is often marginalised compared to other areas of nursing and within the nurse undergraduate training. In this research I anticipate adding valuable data to explore these reasons and assist in stimulating innovative ways to increase recruitment to this area of nursing, both within our unit and within mental health generally.

I have worked in many areas of nursing during my career including medical nursing, paediatrics, care of the elderly, surgical nursing and physical rehabilitation. The majority of my nursing career has been in mental health. I often wonder what aspects of mental health nursing have encouraged me to return to this area. I wonder if they are the same reasons that drive other nurses to work in mental health. Is there a method I can use in my own practice that can have some control over recruitment and retention? By investigating the reasons, I may be able to influence the practices of colleagues to encourage a higher return rate of nurse graduates to this area of nursing.

My research bias sits with the belief that each student placement is a critical time to influence these undergraduate attitudes that may have been coloured by the predominant negative societal views of people with mental health issues. Exposure to consumers of mental health and to practice in these areas may be able to challenge these stereotypical views. By ensuring undergraduate students are supported to spend valuable time with clients, offering role models for this communication may lead to discovery of the reality of mental health issues and the ability to influence recovery for these clients. This may provide the belief that students are capable of making a difference in this area of nursing as well as be able to enjoy and gain a level of professional satisfaction. 
In order to describe this preference to work in mental health and look at some of the influences involved I decided to survey a sample of the nursing population that have chosen to work in mental health. In order to question this group, I have found a questionnaire that will ask the question 'why have you chosen to work in mental health?' Due to the sample population living throughout New Zealand, this approach seems to be the most manageable and inexpensive way to access the group to participate in the survey.

Instead of devising my own questionnaire, I looked through the literature to find a tool that could answer this question. Choice of a questionnaire was limited due to scarcity of research in this area. I investigated replication of a questionnaire that was used in Victoria, Australia in 1999 by Brenda Happell. Happell offered this questionnaire to a group of first year under graduate nurses from universities throughout the state. Because the tool had been used before in similar situations, this has given the tool some validity. I have discussed her study further in the literature review that follows this chapter.

The study I completed is endeavouring to describe the attitudes and influences that make nurses want to work in the area of mental health and therefore create some strategies to encourage recruitment and retention in the area of mental health.

Throughout this thesis I will use the term mental health nursing and psychiatric nursing interchangeably. 


\section{Chapter Two}

\section{Literature Review}

In this chapter I will review literature that I have sourced through internationally refereed scholarly nursing journals. This will give background to what is already known, the quality of evidence that this knowledge is based upon and where the research gaps may be. I searched using key words such as career preferences, attitudes to mental health nursing, workplace choice, recruitment, and psychiatric nursing. From this search it was found that research had taken place in England, Ireland, Scotland and Australia. My literature search revealed no completed or published studies about recruitment or career choices in mental health in New Zealand. This gave me the motivation to use the New Zealand situation to offer a comparison of attitudes towards a career in mental health nursing to other countries.

The amount of literature on this topic was not great in number and there was little recent work that had been completed. My previously mentioned research bias has led me to looking at other topic areas such as nursing student placements, preceptorship and nurse education. This has widened the studies I reviewed and these will also be included in this chapter. The only New Zealand study I have referred to discusses the transition from undergraduate to newly registered nurse.

\section{Personality and attitudes}

The most likely reason for people to choose to work in mental health I thought would be an individuals' personality and their personal attitudes. Personality is a factor that can strongly influence nurses' choices to work in areas of mental health compared to other areas of nursing. Moir and Abraham (1996) have compared the personal attributes of nurses with each type of nursing, highlighting the skills and personality type traits associated with career choice. In the following quote Moir and Abraham refer to the 'in 
group' as being the group which one identifies with and the 'out-group' as being the group which one compares oneself with.

General nursing (the out-group) is routine, technical, and requires less insight and discretion than psychiatric nursing (the in-group) which is portrayed as involving therapeutic acumen and a personal concern for patients. This analysis illustrates the use of descriptions in which the in-group is seen as skilled but relatively deprived (Moir \& Abraham, 1996, p.298).

These findings were achieved by conducting in-depth interviews of 10 entrant and 10 final year nursing undergraduates at a Scottish university. In Scotland, psychiatric nursing is a specialised occupation field that must be opted for in comparison to general nursing training. This interpretative study uses a discourse analytic research approach to look at how student nurses justify their choice to work in this field. The respondents believed they were natural nurses offering a personally enhancing quality.

All the students contrasted psychiatric nursing with general nursing claiming psychiatric nursing allowed more time to develop relationships with patients and develop and apply complex skills. It was acknowledged as an area of unknown science. General nursing was seen as more technical, more task oriented and less challenging. The identity of a psychiatric nurse was thought to be one of developing and being valued rather than being structured and being an auxiliary as in general nursing. The high value of theoretical knowledge and the intrinsic rewards in psychiatric nursing were given a high value compared to those of general nursing.

Clarke (1991) completed a cross-sectional study of attitudes of students from general and mental health training branches in England and compared them using an attitude to treatment questionnaire. The study concludes that some people are more suited to psychiatric nursing than others. Psychiatric students were found to be more liberal than general nursing students. Both groups differ from each other due to attitudes and value systems. 


\section{Most popular areas of nursing}

Mental health nursing features as one of the least popular areas to nurse and this is clearly demonstrated in the studies in Australia as found by Happell (1999) and Stevens and Dulhunty (1992).

In her study Brenda Happell states that the most desirable areas of nursing to work in are those that involve children and babies or technology such as midwifery, paediatrics, intensive/critical care, and operating theatre. The least desirable are in elderly, community health and psychiatric nursing (Happell, 1999). She claims this has resulted from strong preconceived ideas prior to commencing nursing studies. This was found when she administered a questionnaire to first year nursing students in Victorian universities in Australia. Happell based the survey tool that she used in this study on one that had been developed in an earlier study by Stevens and Dulhunty in 1992. The aim of the study was to collect quantitative and qualitative information by requesting ranking of choices for nine different areas of nursing and then the reasons for making these rankings. The relative popularity for each of the preferences was calculated using mean, mode and median. The reasons given were coded into common elements then the frequency was calculated. She discusses the career choice of intensive care unit/cardiac care unit and operating theatre being due to the perception of the importance of saving lives. The most popular career choice of working with babies and children was due to the perceived importance by society of youth, she deducted. The prospect of working in mental health was met with apprehension and fear. She concluded that exposure had minimal effects on these attitudes. The positive aspects of working in mental health nursing were not discussed in this study.

Stevens and Dulhunty commenced a longitudinal study in New South Wales (NSW), Australia, in 1992, and 1994. They found there was a lack of studies looking at attitudes of nursing students to the area of mental health. Their questionnaire, which Happell had adapted for her study above, was presented to new nursing students on their orientation day. They were asked their preference for nursing career from ten areas of nursing and then 
the reasons for their choice. Mental health nursing was rated as nine out of the ten career choices and community mental health nursing was rated ten out of ten choices. No significant difference was found between different areas, different sex or different age groups. The reasons given for rating psychiatric nursing as a first choice was coded into four categories. Their research found, similarly to Happell's, that working with children was the preferred career choice and that working with the mentally ill was the least desirable. Stevens and Dulhunty's questionnaire did not have a section for working with the elderly as with Happell's. Again they have discussed the wider society's views of negativity towards people with a mental illness that has been reflected in the answers by the first year nursing students. Common responses given were fear of the mentally unwell, disgust at the prospect of working with this clientele, emotionally draining, uninteresting, not rewarding and an area of low status. They concluded there were only minor differences in career choice ranking following completion of the nursing course.

The highly technical nursing areas such as intensive care, operating theatre and general surgical are usually associated with curing individuals thus perceived to be of greater importance than the more caring oriented nursing found in elderly, psychiatric and community nursing (Stevens \& Crouch, 1995). This Stevens and Crouch concluded when completing a study investigating attitudes of nursing students towards a career in care of the elderly. They stated that the domain of curing was usually that of the physician, compared to the subordinate role of the nurse being caring, thus perceived as less important. However this does not explain the popularity of working with children and babies, both of which the caring aspect of nursing is prominent.

The decline in numbers of psychiatric nurses has also been explored, trying to find answers to increase recruitment in this area. In one pilot study (Wells, McElwee \& Ryan, 2000) in Ireland comparing conceptions of nursing students, social care workers and school leavers it was concluded that negative societal (as with Happell, 1999, and Stevens \& Dulhunty, 1992,1994) and media views were partially responsible for low recruitment. They also identified poor information through school career guidance. The main reasons the nursing students chose to work in mental health was that either through family contact in the profession; some kind of work experience or they had failed to get a place in general 
nursing and psychiatric nursing was their second choice. The conclusions made from this study was that more positive and accurate information about psychiatric nursing needed to be available to school students and there needed to be strategies for marketing the profession as dynamic, varied, autonomous and non-institutional.

The view that psychiatric nursing is not a highly desirable career is strongly supported by other literature (Campbell, 1971; Carosellini-Karinja, McGowan \& Penn, 1988; Peplau, 1989).

\section{Career pathways}

Examining career pathways may give indicators of reasons for choosing to work in mental health and how to retain those that do remain working in this area. A longitudinal study by Murrells and Robinson (1998) in England, described the career plans and histories of mental health nurses in an attempt to identify strategies to facilitate retention in this area of nursing. They found that a commitment to working in psychiatric settings decreased as the time interval from training increased. The most likely people to remain in mental health areas were nurses that continued to take courses to enhance their chances for promotion. Uncertainty of the direction for mental health services was cited as a reason for lack of confidence to remain in this area of work. This study will be a valuable basis to add further studies to continue to explore reasons for nurses to remain in mental health.

Another longitudinal, qualitative study in the UK by Fergusson and Hope (1999) tracked the progress of students through to competent mental health practitioners and studied their perceptions and their career plans. Nine participants were interviewed at three points: when they had decided to specialise in mental health; when they had completed the year long course and then when the third interview took place a year following completion of the course. Four participants had decided they wanted to work in mental health prior to commencement of the course due to previous work experiences in the area. The most common reasons for the choice was due to the positive experiences during their training, claiming it was 'more interesting', 'more challenging', 'not task oriented', 'more relaxed 
atmosphere', 'less prescriptive', and it 'offered more independence'. Five students had commented they had an interest in psychology or communication. There was a tendency to compare mental health nursing with general nursing making a decisive choice to work in mental health. Although some had experienced some unease in making the decision due to family and friends responses and the concern that they were narrowing their choices for future career options. Seven of the participants indicated they wanted to pursue their career in community mental health.

At completion of the course, they remained positive about their choice but their ideas had matured as they became more aware of the complexities of mental health. They felt they had become more independent and more resilient with the experiences they had been exposed to. They commented on how they had increased in self-confidence due to the smaller class size and the supervised practice experience. Suggestions for improvement in their training were to increase the length of the practicum and to enhance practical skills in psychomotor and communication. The year following the completion of the course all participants were working as staff nurses in mental health, six on acute units and two in intensive care.

Five of the nurses claimed that relationships with clients were the most satisfying part of the work, and the ability of working longer with clients than you could when you were a student. Other positives were working in a team, the variety of clients you work with and teaching and supporting students. The negative aspects were identified as working with hostile, aggressive clients, inappropriate admissions, and having to restrain clients. Ferguson and Hope (1999) have concluded that experience is the crucial factor in making the decision to become a mental health nurse and greater promotion of this areas positive aspects will assist in recruitment. Retention may be assisted with the additional supports of clinical supervision and a planned approach to staff training and education. 


\section{Curricula}

Others have criticised the curricula in mental health baccalaureate programmes. This criticism is directed towards lack of adequate content, relevance to 'reality' and poor consistency of programmes. Prebble (2001), Prebble and McDonald (1997) in New Zealand and Wynaden, Orb, McGowan, and Downie (2000) in Australia argue that undergraduate nursing programmes are not preparing nurses adequately to work within mental health. They believe that the experiences obtained during the undergraduate comprehensive training are not long enough in practicum and do not realistically relate to clinical situations. Prebble (2001) argues that mental health nursing is a distinct scope of practice that requires specialty undergraduate preparation. Throughout the world, psychiatric/mental health nurse training differs greatly in amounts of theory and practice hours that are required (Wells, Ryan, McElwee, 2000; Perese, 1996; O’Donnell, 2003; Happell, 2001; Ferguson \& Hope, 1999; Clarke, 1991). Farrell and Carr (1996) believe education for nurses should be standardised to a worldwide standard. This would ensure a clear agreement on required skills and knowledge to work in this specialised area. The discussion whether mental health nurse training should be separated as a specialty as it is in the UK or within comprehensive programmes as in Australia, New Zealand and the United States continues. Further research and discussion needs to be completed in this area.

\section{Clinical placements}

The importance of the clinical experiences in the undergraduate programmes is repeated in all the literature. Recruitment can be improved by enhancing the student nurse's psychiatric practicum (Lo \& Brown, 1999). Positive factors were identified in this pilot study of Australian undergraduate nurses as: matching theory to situations in the clinical setting; interaction with clients; improvement of knowledge and understanding of mental illness; staff's professionalism, enthusiasm and acceptance of students; diversity of learning opportunities and shift work. Negative factors were related to staff performance. 
Perese (1996) describes similar findings from students' experiences in psychiatric practicums. In this New York study students were offered a questionnaire with open-ended questions to complete following their 6-week psychiatric practicum. The experiences were in both inpatient and community settings and the study was limited to students from only one school of nursing. Over half the students reported that they were anxious, nervous, and fearful as they approached their practicum. The students expected the clients to be hostile, aggressive, in straitjackets and likely to injure them. A third of the students believed that movies or televisions or news stories had influenced these expectations. Generally the students found the area of communication with patients most difficult, worrying if their conversations would be therapeutic for them.

Positive student experiences were identified by Perese (1996) as psychiatrist led team meetings where diagnosis, causal factors, treatment, progress and plans for discharge were discussed. Other positive factors were nursing staff that were professional, enthusiastic and motivated. Characteristics such as being well supported and welcoming; opportunities for client interactions; opportunities for rich and diverse learning were all cited as positive aspects of their practicum. A few of the students talked about the autonomy of the nurse when they had spent time with a psychiatric liaison nurse for the day.

The students identified the negatives as lack of confidence, knowledge, and communication skills. They commented on the unprofessional interactions between staff and "uncaring" interactions with patients. Little time was spent with patients and there seemed to be poor resources available. There were often other students from other disciplines and at times the nursing students felt restricted in times allowed for them to learn. Negative factors identified by Perese (1996) were also the smoking atmosphere, the less structured clinical environment and the powerlessness felt when faced with problems such as stigma, discrimination, isolation and poverty of the clients.

When asked the potentially helpful factors the students identified an increased knowledge prior to practicum surrounding illnesses, medications, therapeutic communication and group leadership. They would have liked longer time on the units, a better orientation, clearer expectations of the nurses' role and the ability to shadow a nurse. Talking with 
other students about previous practicum experiences would be useful, as would have a friend assigned to the same unit during the practicum. The student views held that their overall lack of confidence, preparation and skills have the greatest impact on their impression of the experience being a negative one. This finding gives both the nurses and tutors many areas in which to review current practices in order to meet the needs of the practicum to ensure a positive experience is perceived. This in turn may provide the extra interest that could influence a choice of career in mental health. Due to the size of the study, generalisations could not be drawn from the conclusions. However, this study highlights the challenges for both the student and the clinical staff that is a familiar experience in the clinical area I work.

The small sample size was also a factor in a UK study undertaken by Nolan and Cheung Chung (1999) examining students' perceptions of their first mental health placement in one school. A pre- and post-design was used to administer an attitude to psychiatry, likert scale questionnaire. Despite the limitations and many influences involved in this study, there was a definite conclusion that the student placement was a powerful means of bringing about change towards positive attitudes within mental health nursing. Areas in mental health that were identified as not so convincing were stability of the nurses and the theoretical basis of its practice. Changes noted were the ability to see mental nursing as rewarding, and that mental health nurses are equals of other nurses.

Happell (2001) used her questionnaire to explore the effects of exposure to working in areas of mental health with a pre- and post-test survey. She found that there was a statistically significant increase in popularity following practical experience in this area. This increase in popularity was however not enough to alter the ranking of popularity compared to other areas of nursing. She was drawn to conclude that the recent decrease in nurses choosing to work in mental health might have been due to the change in psychiatric nursing education in Australia in 1993 from a specialty nursing programme to a comprehensive training.

Mullen and Murray (2002) used a questionnaire in a preliminary study to evaluate the experience of a group of Australian undergraduate nursing students in a specially 
developed comprehensive student package. Although the study was limited due to the numbers involved there was evidence that a quality, well-prepared clinical placement programme would make the experience a positive one. Students had commented on the attitudes and the attributes of the staff in the placement that had made a positive impression. These included making them feel welcome, supported, willing to help, educate and be involved in the work. The ability to be involved with clients was also prominent in importance to the students. There was evidence that the experience had encouraged students to consider mental health nursing as a choice for a career and had increased interest by others. This programme had put emphasis on a professional image of mental health nursing as an autonomous, rewarding, challenging and exciting speciality. The placement had a well-organised orientation and an emphasis on using time constructively with a well-planned timetable. Learning objectives were mapped out and a list of team members was available. The learning objectives included psychopharmacology, therapeutic relationship, psychosocial interventions, assessment, psycho-education, psychiatric classifications, early intervention, the Mental Health Act, communication skills, cultural issues, and rehabilitation. At the end of each day the students would be offered a group reflection process to be able to discuss any issues that had arisen during the day. This concept of role modelling was instrumental in increasing the interest in mental health nursing for this group.

Happell and Rushworth (2000) again using the same questionnaire of previous studies by Happell (1999) and Stevens and Dulhunty $(1992,1994)$, claim that exposure and education can increase nurses interest in working in the less desired areas. They used a quasiexperimental research project to look at students' attitudes following completion of a psychiatric nursing unit using a Problem Based Learning approach. A pre- and post- test ranking was used with quantitative data to look at the effects of exposure as to the future career choice. This was undertaken in a comprehensive nursing programme in Australia with the questionnaire administered to first year students at the beginning of the course, then again towards the end of the second year. A limited amount of the questionnaires were cross-matched for a statistical significance. Prior to using the questionnaire a pilot study was conducted followed by focus groups to determine accurate interpretation. Although the ranking of career choices had not changed following exposure to a clinical placement in mental health, there had been a change to a more positive view of psychiatric 
nursing through the answers of the open-ended questions. This was a change in findings from Stevens and Dulhunty's $(1992,1994)$ study. It was unclear whether the difference in attitudes was due to the different teaching approach or other factors involved.

\section{Perceptions of mental health nurses}

Perceptions of the role of mental health nurses can be an important aspect to how students may be influenced to choose future careers. In a qualitative study based on Grounded Theory, Rungapadiachy, Madill and Gough (2004) conducted interviews with students in a diploma programme in the UK. Semi-structured interviews were used to develop a discussion to look at these perceptions. Due to the complexity of this role there has been an avoidance of trying to define the role of a mental health nurse. The themes drawn from the interviews were that the nurse is seen as an administrator, an agent of physical interventions, an administrator of medications, an agent of psychosocial interventions, as a teacher and as an agent of non-therapeutic interventions.

It is these non-therapeutic interventions that need to be addressed to avoid a negative impression of working in this area. Some examples of these practices were alleged malpractice such as physical abuse and intimidation. Non-involvement was cited by Rungapadiachy et. al.(2004) when staff tend to avoid client contact using paperwork as an excuse to sit in the office. It was thought that lack of skill and a negative approach to care added to these non-therapeutic interventions.

The above study highlighted the major proportion of time for mental health nurses was spent giving out medications and completing paperwork. This was put down to resourcing issues and an increase in the bureaucratic role of the nurse. The students were disappointed that their expectations of more psychological interventions were not upheld in their practicums due to these problems. Not only do these negative factors impact on the clients that use mental health services but also it affects the view of students as to how mental health nurses function. 


\section{Preceptor roles}

There is anecdotal evidence that nurses believe there is a mismatch between theory and practice and this can be a cause of disillusionment with nursing and a fear that as a neophyte nurse they are unskilled to work in such a complex area as mental health. It is this complex knowledge adjustment of these concepts within mental health nursing that expert nurses are required to pass on to undergraduate nurses. The combined fear and lack of confidence to gain these skills may be one of the factors that prevent nurses from wishing to work in areas of mental health.

As Benner (1984) writes, referring to her descriptive research with nurses, "preceptors began to recognise that their clinical judgements had become more refined and astute over time. Preceptors began to recognize that their difficulties and even frustration in trying to share their knowledge with newly graduated nurses stemmed from the fact that they were offering knowledge far too complicated to be presented in instructions and cautionary statements to the learner”(Benner, 1984, p.41). The textbook descriptions are usually quite different to the nurse's practical experience due to the variety, exceptions and similar situations.

\section{Recruitment issues and strategies}

Recruitment issues in Australia were highlighted in the National Scoping Study of Mental Health Nursing in 2000. Clinton and Hazelton (2000) reported two major themes from this report - that of high levels of stress for mental health nurses and that nurse education was in need of reform. Recommendations were made from consultations with the Australian and New Zealand College of Mental Health Nurses, stakeholders, consumer organisations, nurse educators and mental health services. A criticism of the study was that there was not sufficient quality data about the workforce of Australian mental health nurses. However strategies were offered as follows: to create a national infrastructure of the planning and development of the mental health workforce; improve mental health nursing education; expand the scope of mental health nursing practice; halt the decline in the mental health 
nursing workforce; attract nurses to regional, rural and isolated communities; and to strengthen the role of the college. The strategies to halt the decline in the workforce concentrated on increasing recruitment advertising, making scholarships available to undertake specialist courses, develop a career pathway, encourage study leave availability and offer assistance to pay course fees. They worried that unless these recommendations were heeded there would be a move to a less professional mental health worker and a decline in standards for consumers. This was the start of an important review process for Australia, similar to changes that had taken place worldwide.

Durkin (2002) offers strategies for psychiatric nursing recruitment based on the literature at the time. She agrees that student interest in psychiatric nursing should be promoted and supported by clinicians and educators. Education about what psychiatric nursing is about to ensure a positive attitudinal shift takes place. Using selective teaching techniques that were proven to enhance the practical experiences may increase interest in this area of nursing. Involvement of the nursing staff in the learning experiences of students was to be encouraged as this was shown to influence students' perceptions. The importance of all these factors was crucial to take into consideration to increase recruitment to this unpopular area of nursing particularly in the midst of a general nursing shortage.

Magnet hospitals have become recognised in the United States of America as one way of recruiting and retaining nurses. The magnet recognition programme (Mendelson, 2003; Aiken, Havens, \& Sloane, 2000) claims to be able to recruit and retain hospital nurses due to its standards of excellence, leadership towards competence of nurses, understanding the cultural and ethnic diversity of patients and the ability to retain the status of a training hospital. This type of programme elevates the nursing profession, the hospital's reputation and has become known to the public as a recognisable benchmark of quality. Not only does it tend to attract nurses and retain them for longer in comparison to other hospitals, it also attracts other disciplines with a 'halo' effect. These positives tend to snowball leading to improved patient outcomes, enhanced staff co-operation, and increased levels of patient satisfaction. This creates a culture that exudes confidence, dynamism, professionalism and respect. 
Perhaps this type of change in culture is what mental health requires; promoting itself to an optimum level of functioning with a strong workforce. This may have some application within mental health particularly as there is a strong emphasis on the implementation of the Mental Health Commission's Blueprint (1997) in order to improve the quality of mental health services for New Zealand.

\section{New directions}

New directions in health care strategies within mental health such as increased specialisation and focus on primary health care will certainly mean that nursing practices will also need to change. Clinical staff and educators will need to work together to adapt to these changes. This could be the impetus we need to change attitudes within our society and present a challenge to promote mental health nursing. I believe this needs to come from within nursing. Due to the disadvantage of being an unpopular choice, mental health nursing will have to work with extra strength to gain a position of popularity.

There are several issues that come through the literature. There are certain personal characteristics and attitudes that indicate a more likely choice of mental health career is pursued. Mental health is not a popular choice within nursing. The general views of our society affect the way mental health is viewed by nursing students. Student placement plays a significant role in students choosing to work in mental health. Undergraduate training methods need a general review throughout the world to encourage some consistency to mental health education.

The literature that I have reviewed has highlighted how little research has been completed on this topic worldwide. There is a lack of recent research within this literature. However there is little change from the most recent to the earlier research that has been completed. The study that I have undertaken is an attempt to bring up to date opinions and attitudes and where we stand in New Zealand in this area. The study by Happell (1999) had similar ideas to those that I wanted to explore. I believed this type of study could assist with answering my question about nurses' attitudes to a career in mental health. Due to the 
similarities in the nurse education system with Australia and the already devised questionnaire, I replicated the study by Brenda Happell from Victoria, Australia. This replication will allow a comparison of findings with similar populations, an ability to monitor any changes over time and will give the evidence extra weight. The replication, or repetition, refers to the design, the survey tool used, analysis and interpretation of data of the research. 


\section{Chapter 3}

\section{Research Design}

The purpose of this chapter is to describe both the research methodology and processes undertaken in relation to this study. These include the selection of the design, identifying the population to be studied, specifying methods to measure the research variables, finalising and reviewing the research plan, conducting the pilot study and making revisions. I will also look at collecting the data and preparing it for analysis.

\section{Survey}

I chose to use a survey in this research due to the following reasons. The survey is the most common perspective taken in nursing to develop knowledge and operates on logic, truth, general principles and predictions. It was pragmatic that I chose this design due to the limit of one year for me to have completed this study. This was a realistic time frame in that the sample group will be available for this time span. This allowed me time to gain ethics approval, send out the questionnaires, and have them returned in time for analysis. The materials required were relatively inexpensive. These materials included paper, stamps, envelopes and use of a personal computer. This is a very low budget of approximately $\$ 35.00$. Due to the small scale of this project, a low cost can be maintained. and access of large numbers of people can be made easily.

A descriptive approach was used to "observe, describe and document aspects of ...." (Polit, Beck, and Hungler, 2001, p. 180) the characteristics surrounding the phenomenon that influences nurse graduates career choices. The survey research approach has the ability to accurately describe this aspect within health care involving facts, opinions or attitudes. 
The data has been obtained through the use of a questionnaire (appendix 1) that I sent out to new graduates enrolled in the New Graduate Mental Health Nursing programme through five educational institutions within New Zealand. The descriptive survey was the most appropriate method in this case as it was able to give "reliable data to use as a basis for future planning” (Sheahan, 1984, p. 106). The survey is a relatively inexpensive method of collecting data from a set population or sample - in this case nurses enrolled in the New Graduate Mental Health Nursing programme.

Usually nurses are interested in knowing patterns of human responses and how to measure these. This is to ensure our nursing practice is able to respond to clients/patients needs and be based on some evidence. Practice based investigations can validate effectiveness of nursing interventions, provide improvements in the quality of care patients receive and improve systems surrounding professional development and education. The questionnaire is commonly used by nurses as it approaches the question directly in order to seek the information required.

Due to my research inexperience, I decided to concentrate on the area that I have a great interest in, the aspect of staff recruitment and retention. This interest has been able to sustain my enthusiasm. I chose the survey research design because it seems logical for me to follow and I believe was able to answer my question.

To give research weight the studies must be repeated to have the outcomes sufficiently supported as being 'fact'. Repeating the study using a different sample population is called a 'replication' study. This gives any findings confirmation and offers the ability for the research results to be implemented where necessary. The replication provides evidence of the effectiveness of the innovation being considered (Polit, Beck \& Hungler, 2001).

The survey I undertook was a replication study of one completed by Brenda Happell (1999). She looked at the reasons nurses choose to work in specific areas of nursing by sampling a group of undergraduate nurses in Victoria, Australia. I have chosen to survey postgraduate nurses in New Zealand using the same questionnaire as Happell but I have 
also added a question to rate their undergraduate nursing experiences and how that has affected their career choice.

\section{Sample}

The group of people I selected to study were the newly registered nurses who have commenced their first year of work as mental health nurses since registration. This group is known as the sample. They are representing the larger group, known as the population, which is mental health nurses in New Zealand. Due to the need to keep this study small, inexpensive and within the time limit of one year, from this group I selected a portion to represent the whole population. This group, the sample, was easily accessed due to them having a set time that they attend class for non-clinical study. The selection process was specific in that this sample of nurses are those that have chosen to work in the area of mental health nursing and were enrolled in the entry-to-practice programmes throughout New Zealand.

My belief is that the questionnaire that I offered to this sample was able to extract information that could lead to generalisations of the larger population of mental health nurses from their answers about career choices.

The information I obtained to gain access to the sample was gained through the Ministry of Health website that lists the programmes that are CTA funded. The website was last updated in October 2004. The name of the programme at that stage was the New Graduate Mental Health Nursing Programme. This is an entry-to-practice programme at postgraduate certificate level offered to nurses with less than six months experience within a mental health setting. The nurses are employed as health professionals in clinical areas of mental health during their yearlong course, but are enrolled with a tertiary educational institute for their non-clinical studies. There were eight providers listed on the website and 
these ranged from technical institutes, polytechnics, universities to district health boards divisions of geographical health areas that are funded by the government. There were approximately 140 new graduates enrolled in the course for 2005 throughout New Zealand. The programmes proceeded from January until November in the same year.

My first contact was through a standard e-mail personally addressed to the contact person named on the website. In this e-mail I said I would follow up with a phone call in the following week. The selection of the sample group was made clear to the co-ordinators of the courses in order that they could give advice to the process to gain access to these students. Through these phone calls I was able to gauge the support that was going to be offered. The overall attitude to this research was very positive and this gave me extra energy to progress. Many of the people that I spoke to had also completed their masters' studies and acknowledged their interest in the topic as well.

This initial contact highlighted the deficiencies in relying on the website for contacts. There were three names that were no longer in the positions stated. Using the contact phone numbers and making further enquiries overcame this problem.

A further factor to be considered was whether the research question was concerning the students' employment or their education. This was important so the contact person could guide me as to which ethics approval process would be required. My decision was that the question was about the students education and why they had enrolled in this course initially, thus I saw them as students.

\section{Ethics}

In order to complete research with human participants, consideration needs to be given to ensure no harm will be done to participants or the community that the research is 
completed within. This is a protection for the clients and community that the research sits within. This process is also to protect the researcher from any unjust criticism from the community. In this next section I will describe the ethics process and discuss how I have considered the ethical principles that influence this nursing research.

Application for approval of this research project was completed through the Human Ethics Committee of Victoria University of Wellington. The nature of the proposed research, the investigator and supervisor was named and the duration of the research was stated. The application was completed in March 2005 and was approved in May 2005 (appendix 2). This approval continued to the 31 January 2006. This was the timeframe that the research must be completed within.

Any sources of funding were required to be declared. No funding was required with this research. The researcher donated movie passes.

Ethical approval was required from the educational institutes that I gained access of the students from. This was accessed through the Heads of Schools of Auckland University, Otago University (Christchurch), Otago Polytechnic (Dunedin), Eastern Institute of Technology (Napier), and Whitireia Polytechnic (Porirua) and their respective ethics committees. As the sample was to be drawn from these five educational institutes, I sent the ethical approval (appendix 1) obtained from Victoria University to their relevant ethics committees prior to commencing this study.

The application assures the Human Ethics Committee that all ethical issues have been considered as in the following paragraphs, i.e. confidentiality, anonymity, informed consent, consideration of the sample. At all times research must have respect for persons involved in the research as well as the community. The research should also be beneficial and shall do no harm. There must be personal caring in the wording of documentation so 
that the reader experiences no offence. It should be fair to the participants and community as a whole. Any results that affect the perception of the community or recommend change to the methods of health care delivery to the community should be considered respectfully (Polit et al., 2001).

The aim of this study was to benefit both health professionals and the community by ensuring thorough examination of the ability to maximize the number of staff working within mental health. Consideration was taken of the social attitudes that were identified through this research and thus was respectful of the participants' views. If any negative attitudes evolve from this research, the findings must be relayed in a style that will offer constructive feedback rather than a destructive positioning of the research.

These ethical considerations have evolved from events in history that have exposed vulnerable groups to research experiments (Declaration of Helsinki, 1965). Legislation has been put in place to ensure the protection of these groups such as the Nuremberg Code that was developed to protect the concentration camp prisoners from the atrocities performed by Nazi physicians. The Declaration of Helsinki was adopted by the World Medical Assembly in 1965 to protect people undergoing medical research. This continues to be used today in a revised form for all medical research worldwide. Most professional disciplines have their own code of ethics that guide their practice.

The Nursing Council of New Zealand includes ethics in their Code of Conduct (2005). The Nursing Council is the statutory authority that governs the practice of nurses, sets and monitors standards in the interest of the public and the profession within New Zealand. The council's primary concern is public safety. During this research, I have complied within any legislated requirements, acted ethically and maintained standards of practice, respected rights of any clients involved and justified public trust and confidence as stated in this code of conduct. 
The principles within these codes ensure that basic human rights are protected and respected. In order for the participants in this research to consent to the process, they need to be informed and to participate voluntarily. Informed consent in this study was obtained by supplying participants with an information sheet to accompany the questionnaire, consent was then assumed by the participant's completion and return of the questionnaire.

As the questionnaires were given out by the co-ordinators of the course, I had supplied a suggested method to deliver these to the students to ensure consistency. However due to individual styles of teaching, there may have been differing approaches. The students' perceptions of the survey may have been influenced by these approaches. This is unable to be avoided. The recommendation from the included directions was to stress to the students that completion of the questionnaire was entirely voluntary. However the relationship between student and lecturer is often viewed as having an unequal power balance. Thus there may have been created a pressure to complete in order to ensure a favourable impression to the lecturer from the student. There also could be similar pressures from their peers in the same respect. In order to reduce this possible discomfort and make the completion truly voluntary, I enclosed an envelope for the students to place the completed questionnaires in prior to returning to the co-ordinator/lecturer. In this way if the participant had decided not to complete, then this would not be obvious to others in the classroom.

Due to the small sample size there may be ability for some of the participants demographic information to make them recognisable. These identities were not linked to the information they provided when written in the summary or thesis findings. Each of the questionnaires was coded as a number when received to reduce the ability of the researcher to link these to specific areas. Data was analysed as a group so as individuals were not identified by their responses and was documented in a way that cannot be identified as coming from the individual. Anonymity, "the identity of the participants will not be able to be linked, even by the researcher, by the individuals responses” (LoBiondo-Wood \& Haber, 1994, p. 324), was maintained by each of the questionnaires being individually coded by their student identification number which the researcher has no knowledge or ability to link. Names of participants were not disclosed during any of the research. 
Confidentiality, information being publicly divulged linking individual's identities, was not an issue due to the survey being anonymous.

Storage of all written material such as questionnaires was kept in a locked file and access was restricted to the investigator. All electronic information was kept in a passwordprotected file and access was restricted to the investigator. At the conclusion of the research all questionnaires and associated materials was destroyed.

The feedback was provided to the participants in a summary of findings that was mailed to the co-ordinator of the programmes involved. The results will be reported in a publication in an academic or professional journal and disseminated at an academic or professional conference and the thesis will be deposited in the Victoria University of Wellington Library.

The majority of providers were happy with awaiting ethics approval from Victoria University Human Ethics Committee and then citing this ethics approval with a request letter to their own ethics committees. One educational institute wanted the research project to go through their own ethics committee, which gave approval (appendix 3)

\section{Treaty of Waitangi}

The Treaty of Waitangi is the founding document of New Zealand. It was signed in 1840 at a time when Maori (native race of New Zealand) far outnumbered Pakeha (non-Maori) settlers. The Treaty was the bargaining document that was signed between Maori and the British Crown as settlers were increasing in numbers in New Zealand. The Treaty outlined the principles that would enable these two races to live together ensuring the rights and obligations of both groups were upheld. There have been differing interpretations of the treaty over the years that have led to further legislation to ensure the principles of the Treaty are upheld. 
The Maori people believe that their race has been disadvantaged in many ways since the signing of the Treaty and Maori health is an area that has shown decline in comparison to the non-Maori population. Ensuring consideration of the Treaty principles has become an integral part of all areas of health within New Zealand in an attempt to address this disparity. For this reason, I have included consideration of the principles of the Treaty in this research.

Historically, Maori have a disproportionately higher rate of mental health problems compared to the rest of New Zealand's population (Ellis, P. \& Collings, S. 1997). Acknowledgement of these statistics is required to ensure culturally appropriate care is provided for Maori. In order to meet Treaty obligations to protect Maori, we need to respect the right to quality health care which is one of the aims of this research indirectly by ensuring adequate numbers of registered staff to ensure well being and recovery as an obligation on the Crown from the Treaty.

The Treaty principles of partnership, protection, and participation was incorporated into the research by seeking informed consent from participants, maintaining confidentiality of the data (including dissemination of results) presenting information about the project and seeking feedback from cultural advisors.

There was the expectation that there would be a percentage of Maori registered nurses that would agree to participate in this research from the sample I have chosen. Consultation took place by discussion with Maori staff from the service I work for. Pacific Island nurses also made up some of the sample thus consultation with an appropriate cultural advisor also took place. 


\section{Questionnaire}

I made contact with Dr Brenda Happell (personal communication, early February, 2005) to request permission for use of the questionnaire for this research project. Approval was given and the original questionnaire was faxed to me. The format and appearance of the original questionnaire that Happell had used required some modifications prior to administering. The alterations were completed to make it clearer, more professional and to improve the quality of the appearance. The questionnaire was printed on both sides of the paper to give the impression that the document was not too long.

Questionnaires are made up of a series of set questions and provides a space for an answer, offers a tick box or a choice to be circled. They can be completed group settings, mailed to respondents or read to respondents by interviewers over the phone or in person (Gillis \& Jackson, 2002, p. 137).

The characteristics of the questionnaire should be designed to extract information that is relevant to the study. There should only be questions that will contribute to data collection. The questionnaire should be quick to complete. The design should encourage the respondent to willingly complete the form, be easily understood, unambiguous, and ask for information that can be recalled easily from memory.

The questionnaire that has been used has the information sheet attached to the front page with purpose and importance of the research outlined. It also supplies clear instructions and assurance of ethical factors such as anonymity. This leads onto the actual questions on the next page. There are reasonable spaces left between each question to make the design more attractive. Spaces left for the answers to the questions are ample to allow for individual styles of writing but not too large a space as to intimidate the participant to add extra comments. There is the opportunity at the end of the questionnaire to add any further comments if the participant has not the required space for their answers by offering to use the back of the questionnaire. 
The questionnaire used in this study (appendix 1) took approximately ten minutes to complete with a total of ten questions thus falls into the category of being brief and quick to complete. The first three questions of Happell's questionnaire are demographic, singlechoice or closed-ended questions. This choice makes the completion of the questionnaire more likely as these are quick and easy to answer, requiring little thought.

The slightly more complex questions follow with rank-ordering questions to list the nurse's preference to work in specific areas. Nine areas of nursing are selected and the participants are asked to number the most preferred area to work as a $\mathbf{1}$ and the least preferred area to work as a 9. These areas are: in operating theatre; in midwifery; with children; on general medical wards; in psychiatric nursing; in intensive care/critical care; with the elderly; on general surgical wards; and in community health nursing.

Then the most complex, open-ended questions are asked - "what reason?” of the most preferred; least preferred; psychiatric nursing; intensive care nursing options. These provide a qualitative dimension to this study in that the participant is asked their opinions without categories being pre-determined (Gillis \& Jackson, 2002, p.476). By leaving these questions near to the end, the respondent will have invested some time already to completing the questionnaire and may be more likely to complete these longer, more thought provoking questions. It also allows time to consider the earlier questions and offers the ability to add on any further opinions.

Finally, a likert-type scale was used to rate the clinical placement in their undergraduate programme with a space to comment on their experience. Four choices were given: excellent; satisfactory; not satisfactory; and poor. This question was added to the original questionnaire. 


\section{Survey Administration}

A pilot study was completed prior to the survey using the questionnaire. I engaged five colleagues that I work with to make up this sample. I checked with them that the instructions were clear; questions were not ambiguous, if there were any objectionable questions and any areas that I had missed. I also checked how long they took to complete the questionnaire. From this pilot, I adapted the questionnaire and the categories to assist in the data collection and analysis as required.

Permission had to be gained from the lecturers involved in handing out the questionnaires as well as their head of departments. This was due to this research being outside of the accepted curriculum and handing out the questionnaire (appendix 1) would take up some of the normal study time. I needed permission to use the educational institute time for this research. I anticipated this research would take ten minutes of lecture time. I needed positive support in order for the distribution of the questionnaires to the students and to gain support from participants to increase the willingness to complete the questionnaires.

I found that three district health boards listed as providers worked through Auckland University. Thus permission for these areas was simplified by having to apply to only one head of department. The head of each school were sent a letter to request permission for the research to take place within school non-clinical time. Accompanying this letter would be a copy of the ethics approval from Victoria University, the questionnaire with participant information sheet and the instruction sheet for the co-ordinator. Once I had this approval, I sent the questionnaires out to the course co-ordinator with a request that they give the questionnaires out to the participants. In the mail out to the co-ordinator was an instruction sheet, the questionnaire with participant information sheet and a letter to outline the research, envelopes to place the completed questionnaire in, an envelope to place the tear off slip for the prize draw and a stamped, addressed return envelope. 
The questionnaire was presented to the students by their programme coordinator/lecturer during their non-clinical study days. An information sheet was supplied with the questionnaire and informed consent was implied by voluntary participation in filling out of the questionnaire.

In the instruction sheet to the coordinator/lecturer, I suggested that the person giving out the questionnaire administer it at the end of a session of classroom time. This allowed the students to finish in their individual time instead of having to be pressured to finish at the same time as the other participants. It also ensures that the classroom session is not disrupted. Although there was the risk that at the end of the session, people may be tired or bored or wish to leave the classroom as soon as possible, thus less likely to complete the questionnaire or start it.

There was an incentive to complete the questionnaire included in the way of a draw for a double adult movie pass. If the questionnaire was completed and their student identification number is written in the space provided, participants were eligible to be placed in the draw for the movie pass. This way the research remains anonymous, as the investigator has no knowledge of the participants' details. The draw took place following all the questionnaires having been received. Three adult, double movie passes were available and the winning draw was notified to the coordinator/lecturer by way of student identification number. The co-ordinator/lecturer then notified me by e-mail if the student was from their programme and I sent the prizes by mail to the coordinator/lecturer to give out to the recipients.

There was a delay in commencing the survey with one particular group of students due to the research project needing to go through their educational institutes own ethics committee. Instead of getting the questionnaires out to the students in their non-clinical study in June, there had been a delay until August. 
The co-ordinator of the delayed group offered to send the questionnaires out to the participants in the mail to speed up the process but I decided that this would not be consistent with the rest of the survey. Having a consistent approach to all participants ensures internal validity of the test. This control is accomplished by ruling out extraneous variables, such as differing data collection processes. I decided to use the same process as with the other questionnaires, a group administered method. Added to this, mail out surveys tend to have a lower response rate (Gillis \& Jackson, 2002, p. 148), which I wanted to avoid.

\section{Data Collection}

The data was transferred to a spreadsheet. I chose to use this method due to the ease of reading the results on one programme and the ability for the spreadsheet to assist with analysis and designing charts. Organising the spreadsheet to resemble the questions in the questionnaire completed this. As each areas questionnaires were returned, I numbered each returned questionnaire to aid in administrative procedures. To avoid errors in data input, I input only ten questionnaires at a time. Following this process, I read back over those ten to check the accuracy of the data that had been entered.

All data collected during this research was stored securely in a locked cabinet or electronic information was kept in a password-protected file with access restricted to the researcher as per ethics committee requirements. All questionnaires, interview notes and similar materials were destroyed once data collection was completed, as mentioned earlier in the ethics section. 


\section{Analysis}

The decision was made that a response rate of $80 \%$ would be an acceptable rate to complete analysis of the questionnaire. Group administered questionnaires almost always have a good response rate as mentioned previously. This is probably due to the informal peer pressure to co-operate with the researcher (Gillis \& Jackson, 2002, p.146). However in this study the researcher is not the person presenting the questionnaire, eliminating the possibility of researcher bias. Therefore I have used less than the expected 90 to 100 percent returns that can be expected when a researcher gives out the questionnaires. Due to the survey being a nationwide study, the expense of travelling to the geographically spread areas would have been high. Instead I posted out the questionnaires to the areas throughout New Zealand.

Analysis involved descriptive statistics including frequency distribution. Conclusions were drawn from the descriptive and evaluative findings and this was written up as a summary. This summary of findings was mailed to the co-ordinator/lecturer of the programmes, to distribute to the participants. Through the use of the spreadsheet, I was able to describe the measures of central tendency of median, mode, mean, range, frequency distribution and percentages. My intention was to use chi-square to test the statistical significance between the levels of satisfaction of the student placement to the sex of the participants. From the open-ended questions, I grouped the answers and calculated the frequency for each response. 


\section{Chapter 4}

\section{Results}

A total of 101 nurse graduates were recruited to participate in the study. Participants were chosen from the entry to practice programme for mental health nursing throughout New Zealand. The 101 participants represented $75.65 \%$ of the total population that was enrolled in the Clinical Training Authority (CTA) funded programme nationwide. The ages ranged between 20 and 55 years and the average age was 36 years. There were $87.1 \%(\mathrm{~N}=88)$ females, $11.8 \%(\mathrm{~N}=12)$ males and $0.99 \%(\mathrm{~N}=1)$ has not stated their sex.

\section{Response rate}

The actual return rate of the questionnaires returned from those sent out was calculated as $65 \%$ as they came in the mail. Following the final returns of the questionnaire, I rechecked with lecturers as to how accurate my figures were by requesting the exact numbers of students offered the questionnaire. This eliminated the students that had not continued with the course or those students absent on the day the questionnaires were offered. Thus I have calculated that the overall response rate is $\mathbf{7 5 . 6 5 \%}$. Meeting the predicted response rate would be excellent, however to be within $20 \%$ of the predicted response rate can be considered acceptable (Gillis \& Jackson, 2002, p.150). This is well within the acceptable response rate as my expected response rate was $80 \%$.

\section{Data Organisation}

To ensure rigorous processes were maintained during data collection, these are the steps I followed. As the questionnaires were returned, I checked them off on a checklist. This 
way, I was able to keep track of my response rate and how many questionnaires were yet to be returned. I maintained a mail checklist with which documents I had sent to whom on which date and when the returns had come back in.

As I opened the envelopes with the questionnaires, I numbered each of the questionnaires. This method allowed tracking of each return to enable the response rate to be calculated. I was not able to identify each of the participants. Although this has meant that there was the ability to identify the area that these questionnaires came from. This will not be used in the data analysis.

I placed the tear-off slips with the participant's student identification number in the prize draw envelope and put this to one side.

As I opened the envelopes I had a quick look at the answers. The information seemed similar to other research that I have looked at. I also was able to gauge how many of the participants had filled in the tear off slip for the prize draw for an adult double movie pass. The percentage of people completing this was low, in comparison to the study that has been replicated, at $71 \%(\mathrm{~N}=72)$ of all completed questionnaires. One of the coordinators requested that all of her group of students returned questionnaires go in to the prize draw. She stated that they did not have their student identification number with them. The process I used to solve this problem was to use the coding system that I had put in place and if one of those coded return slips was chosen then I would use the statistics of age, sex, ethnicity and previous nursing experience for the coordinator to be able to identify the winner.

Once all the questionnaires were returned, I was able to make the prize draw. All student identification numbers were folded into small squares and placed in a large bowl. The slips that belonged to the group that did not have their student identification numbers with them had been coded according to when returned, were also folded into squares and placed into the bowl. A member of my family was able to make three draws from the bowl. Each slip that had been drawn had a student identification number. 
These numbers I then e-mailed to the co-ordinators of each group. The response from the winning areas came back quickly. I then mailed the adult double movie passes to the coordinators that had responded.

I started data input when I had received the majority of returns. I used Microsoft Excel spreadsheet to record the data. This enabled organisation of information into categories. It also was able to assist with data analysis. My data input process was a methodical approach, in which I would input ten questionnaires at a time, and then take a break from the computer, then return to check for any errors or missed information. This also allowed time to refresh from this tedious task.

As the data was reported into the system I could complete a crude initial analysis as follows. The statistics showed the participant population was made up of a wide ranging age group, but a large proportion were of middle age. The main sex represented was female; one participant did not state their sex.

Missing data in this study refers to when the participant has not completed one or more items on the questionnaire or the question had not been answered as requested. When this occurs, the researcher is unable to make any generalisations from the information provided. If there are questions that have not been answered or have been answered in a different way to what is expected, a decision had to be made how to handle this eventuality.

The decision as to what to do about missing data involved discussion with other researchers and my supervisor. The decision when the answer to the question had not been included or omitted was to remove that questionnaire from that item of discussion. This was due to not being able to estimate what the missing data may have been. I have decided to eliminate those rankings that do not conform to the question asked. Where the question had been answered without following the instructions, but the data could be clearly interpreted this would be included. This is termed data imputation. If this could not be done clearly, then that data would be deleted and named missing data. There were seven questionnaires that I removed in this question due to missing data. 


\section{Age/Sex distribution}

The age distribution for this sample population is shown in graph 1 . There are two peaks, one in the twenty to twenty-nine year age group and one in the forty to forty-nine age group. There is an even distribution of those aged over 35 years as to those aged under 35 years that have chosen to work in psychiatric nursing. When I grouped these ages into tenyear age groups (graph 1) there was a trend with equal numbers in the twenty to twentynine age group and the forty to forty-nine age group. The thirty to thirty-nine age group was only $15 \%$ less in number. Thus the age distribution was fairly even across the sample group between ages 20 to 49 years. Those that stated they were 50 years or older were the smallest proportion i.e., $10 \%$ of the greater group size. There is a bimodal distribution across the age groups of this sample. The peaks are at mid twenties and mid forties with an average of 36 years. This is in sharp contrast to the groups that were sampled by Happell (1999) where seventy-seven per cent of the sample was aged between 17 and 23 years. Less than $12 \%$ were over the age of 30 years. The sample in the study by Stevens and Dulhunty (1992) had an average age of 19 years. This is due to a slightly different sample group in that in both of their studies they sampled first year undergraduate nurses and in this study I have sampled first year postgraduate students.

There are fewer nurses in the 50 years and over age group in this study, as expected, as less people are willing to start a new career at this time of life. The people in this latter group however may be people that have worked in mental health for many years and recently have decided to increase their learning and professional development by completing their degree and looking at further development. Only $20 \%$ of this age group sample however indicated in the questionnaire that they had earlier experience in mental health, either as mental health support workers or enrolled nurses.

I have also included the sex of the participants in this graph. There was an even distribution across the age groups from 20 to 49 years but no representation of males in the 
50 years and over age group. The average age of participants is 36 years with a range between 20 and 50+years.

\section{Graph 1. Age/Sex distribution}

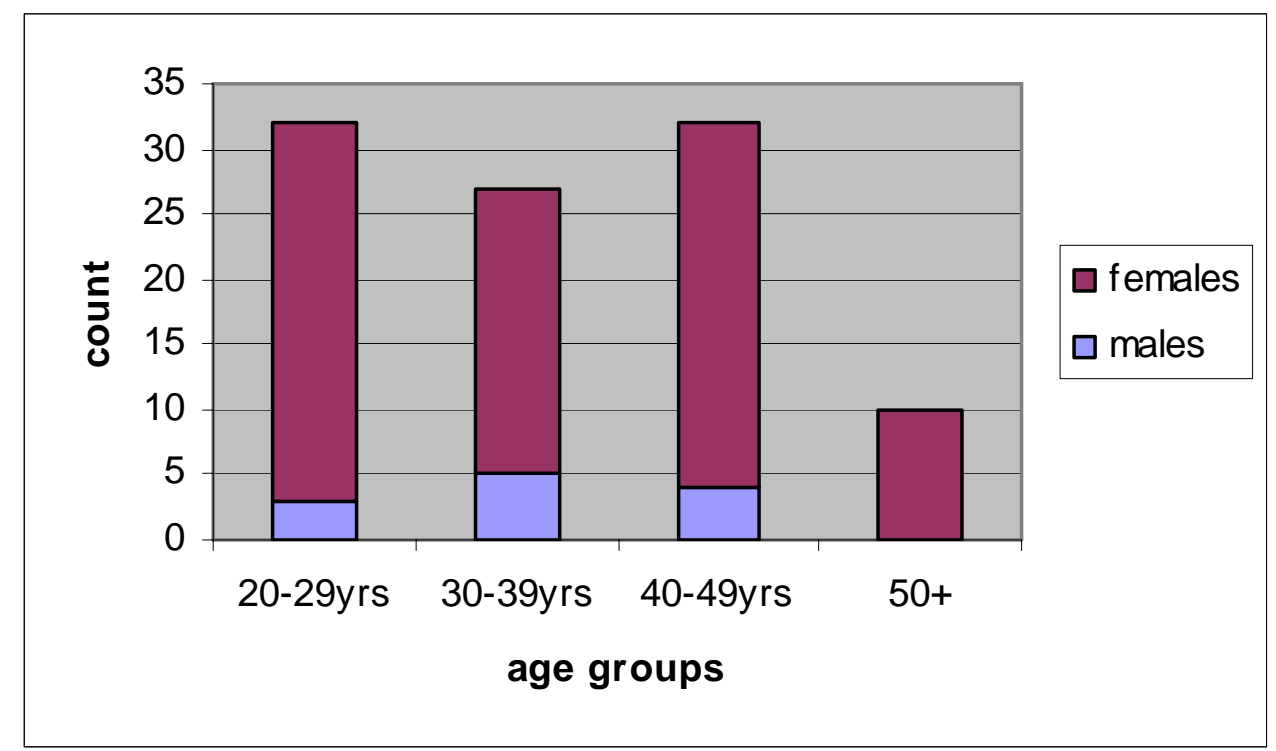

\section{Ethnicity}

New Zealand is a multi-cultural country at present. The history of New Zealand's cultural make-up has been determined by its geographical situation (King, 2002). The Polynesian indigenous race of the Maori was quickly overtaken in numbers by the British Anglo/Celtic settlers in the 1800's. During this bi-cultural stage of New Zealand's history the races lived separately and their cultures were quite distinct. The Pakeha (non-Maori race) were the dominant race in that they were the city dwellers, lawmakers and insisted that the spoken language was English. When other cultures such as Dalmatians, Jews, Italians, Chinese migrated to New Zealand, they were encouraged to live the European lifestyle. New Zealand soon became involved in the administration of many of the other Polynesian islands such as Samoa, Cook Islands and the Tokelau Islands. Thus the relationship between New Zealand and these islands led to a significant permanent migration (King, 2002). As well, many Asian countries developed relationships with New 
Zealand, which has also led to further population movement from Asian areas. Following World War II the Maori peoples started moving into the cities from the rural areas and this has created the multi-culturalism we have today. The proportion of the general New Zealand population today is as follows: European $=79 \%$, Maori $=15 \%$, Pacific Island $=$ 7\%, Asian = 7\% (Statistics New Zealand, 2001).

From the demographic data collected, this range of ethnicities was evident. In this studies questionnaire, the ethnicity question was an open-ended question and as such created a range of twenty-seven groupings. Many of the participants have listed multiple ethnicities e.g. Maori/Irish/French. The ethnicity question I added to the original questionnaire that was used by Happell (1999).

The ethnic concept used in surveys is the ethnic group or groups that people identify with or feel they belong to. Ethnicity is self-perceived. For example, people may identify with the Maori ethnicity even though they may not be descended from a Maori ancestor. Conversely, people may choose to not identify with the Maori ethnicity even though they are descended from a Maori ancestor. Ethnicity does not equate to a birthplace description.

Table 1. Number of Ethnic groups identified by participants

\begin{tabular}{|c|c|c|c|l|l|l|l|}
\hline NZ/European & Maori & $\begin{array}{l}\text { Pacific } \\
\text { Islander }\end{array}$ & Asian & $\begin{array}{l}\text { North } \\
\text { European }\end{array}$ & $\begin{array}{l}\text { North } \\
\text { American }\end{array}$ & African & $\begin{array}{l}\text { Not } \\
\text { stated }\end{array}$ \\
\hline 66 & 25 & 7 & 9 & 10 & 1 & 1 & 3 \\
\hline
\end{tabular}

People can and do belong to more than one ethnic group. In this sample a large group identified with the Maori ethnicity. Of these people a group also identified with a European 
ethnicity. Similarly some people who identified with a Pacific ethnicity also identified with the Maori ethnicity. People who identify with more than one ethnicity could be included in each ethnic population. Therefore these ethnic projections would not be mutually exclusive. From the replies in this study I have grouped the ethnic identities into eight categories (Table 1). I have counted each ethnic group as one, that is, if a participant has listed Maori/French/European as their ethnicity, this will be counted as 1 Maori, 1 North European, $1 \mathrm{NZ/European.} \mathrm{Many} \mathrm{have} \mathrm{overlapped} \mathrm{and} \mathrm{thus} \mathrm{had} \mathrm{added} \mathrm{up} \mathrm{in} \mathrm{total} \mathrm{to} \mathrm{more}$ than the 101 number of returned questionnaires. The population spread is shown as similar to the general population distribution.

\section{Preferences}

The workplace preferences are calculated by counting the number of participants choosing each area of nursing in first, second and third rankings (graph 2). In this graph the value (horizontal) axis represents the number of participants that choose the specific area of nursing. The category (vertical) axis represents the areas of nursing that were categorised in the questionnaire. The participants were asked to rank these areas of nursing in order of preference from 'one' as the most preferred to 'nine' as the least preferred. Psychiatric nursing was chosen as first choice by $83.16 \%(\mathrm{~N}=84)$ of the sample. No participants chose midwifery or elderly as their first choice of area to work. The areas of medical, community and children each had two participants choosing them as first choice. Operating theatre, intensive care and surgical areas of nursing had one participant choosing them as the first choice to work. The second choice was clearly ranked as the community area of nursing by the majority of participants, as $31.68 \%(\mathrm{~N}=32)$ of participants made this choice. Elderly and children were the next highest-ranking areas to work as second choice. Psychiatric nursing was ranked as second for three participants. The third choice was evenly spread between community, medical, children and midwifery areas of nursing. In graph 2 where participants have made their second choice, there is a significant ranking of community as the next most preferred option. 
In graph 2 the third choice of areas to work, there is an even spread between the areas of community, medical, children and midwifery. ICU, surgical and elderly are the least popular choice for this group of participants.

\section{Graph 2. Nursing career preferences}

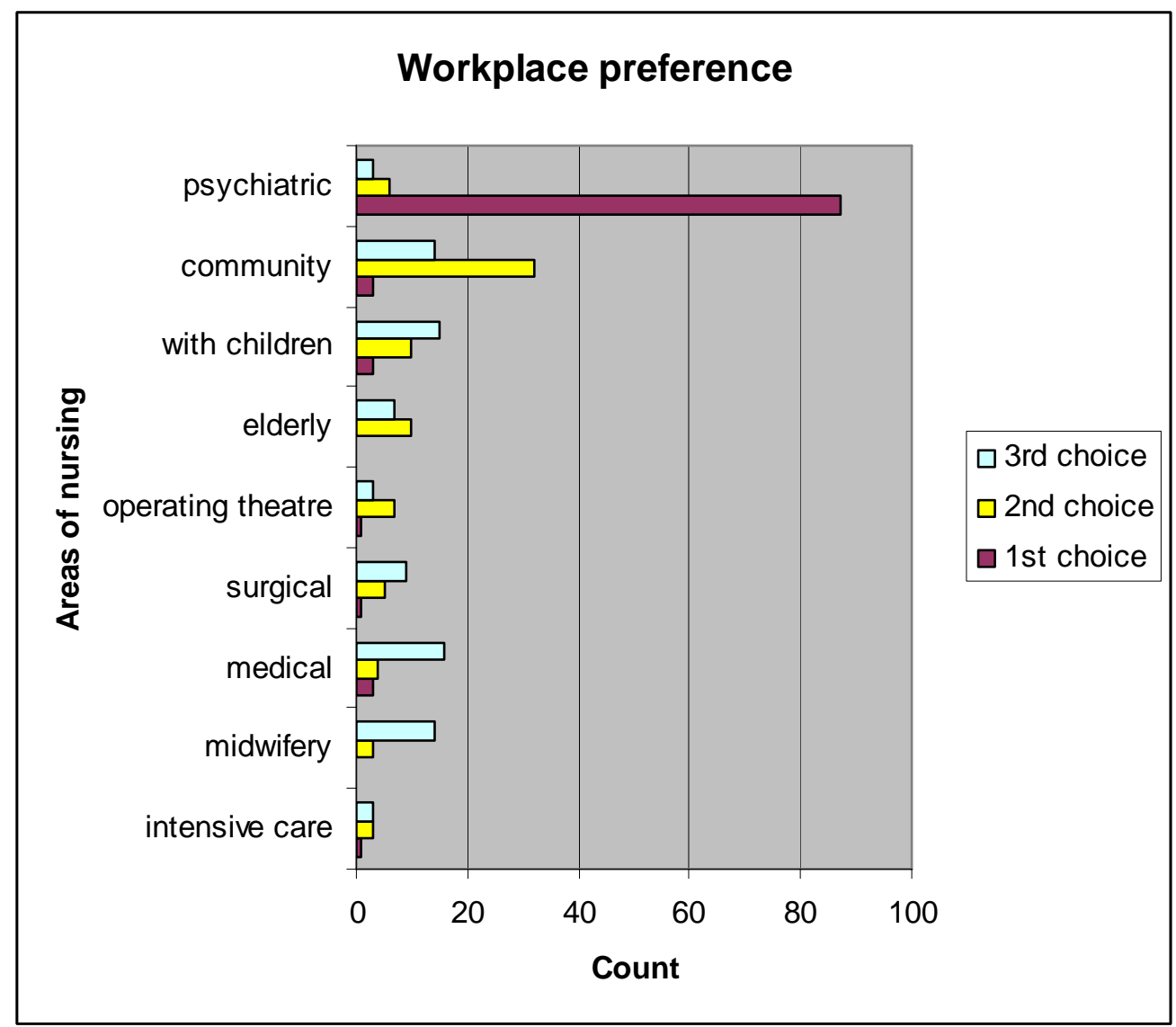

Graph 3 provides more representative information about the popularity of areas of nursing as a career choice for this sample of nurses. Again the category (vertical) axis represents the area of nursing that were categorised in the questionnaire. The value (horizontal) axis represents the ranking score that each of the participants gave each of the areas rated between 1 and 9 , ' 1 ' being the most preferred and ' 9 ' being the least preferred area to work. If the mean is greater than the median then the distribution is positively skewed as with ICU, medical, surgical, children, community and psychiatric areas. The skewness describes the shape of the distribution of population. If the mean is less than the median, then the distribution is negatively skewed. Markedly skewed data indicates that the mean is not a good measure of average (Munro, 2005) as was found with the choice of psychiatric nursing in this study. Mode tells us which rankings occur most frequently. Although this 
is interesting to know that the areas of children, elderly, operating theatre and midwifery have the most rankings of eight and nine, it is not as accurate a measure of averages. The median is the most accurate measure due to its stability and there not being a continuous measure and there is a set distance between each measure.

\section{Graph 3. The relative popularity of nursing career choices}

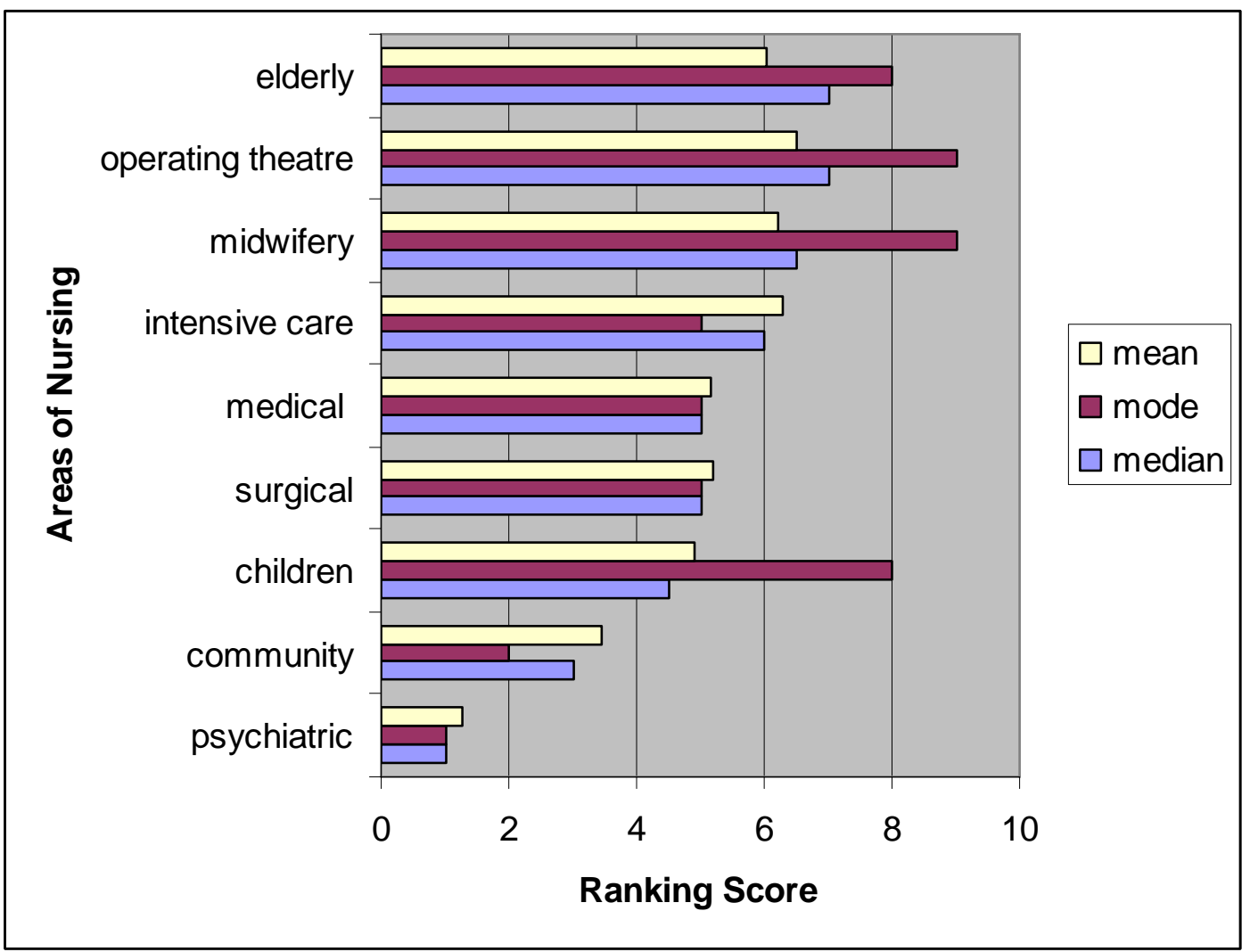

It is clear from the median values (graph 3) that psychiatric nursing is the most preferred area of nursing with the median value of one. Community nursing ranks as the second most popular with a median ranking value of three. Nursing with children is third choice with a median value of 4.5 ranking score. Medical and surgical areas sit together ranking at the median rank of fifth. Intensive care follows closely behind these three groups with a median value of sixth ranking. Midwifery is one of the least popular areas of nursing for this sample group. Median rankings of career choices show that elderly and operating theatre are the least attractive areas with median value of a rank of seven.

The mode measurement in this study is almost opposite to the measurement completed in the study by Happell (1999). The mode for children, midwifery, operating theatre is ranked at between numbers 1 and 3, whereas in graph 3 they are ranked as either at number 
8 or 9. The median ranking scores indicate that psychiatric, community and children are the most popular choices in this study compared to Happell's with children, midwifery, ICU and operating theatre being the most popular choices. The mean rankings show a similar pattern to the median measures in both studies.

In the graphs above, the preference by the participating sample group is psychiatric nursing as expected. The surprising data shows that other areas than psychiatric nursing are rated as number one. Thus showing that the choice has not always been a willing choice. Through the open-ended questions the reasons for this are: "the inability to get into similar programmes in general nursing"; "high expectations for more specialised areas"; and "the desire to have psychiatric knowledge prior to working in more generalised areas of medicine”.

\section{Reasons given for the most preferred option}

This question asked for the reasons that participants chose the most preferred option, referring to the earlier question requesting participants to rank the areas of nursing to work in. As found from the earlier results shown in graph 3, 83.1\% $(\mathrm{N}=84)$ of participants chose psychiatric nursing as the preferred option. Most of the participants wrote more than one reason.

In order to analyse these answers, I identified comments as having similar themes and grouped these into five broad categories. These were: professional; self-satisfaction; specific skills; personal; and comparison to general nursing. These categories were similar to those discussed by Moir and Abraham (1996). These comments have been grouped into the table below numbered 2(i) to 2(v). Despite these groupings, many of the comments could be categorised into more than one of these areas.

'Professional development' reasons made up $11.98 \%$ of comments given as shown in table 2(i). 
Table 2. Reasons given for the most preferred option

\section{2.i. Professional development}

\section{Reasons given}

achievable academic move

$N Z$ has a progressive approach in $\mathrm{MH}$

more respected as a profession

add to counselling qualification

expand knowledge in $\mathrm{MH}$

interested in continuing nursing career

implies continuous learning

extend practice

programme will hold in good stead

previous experience in $\mathrm{MH}$

lots of options

highly skilled area

room for change

example provided by enthusiastic undergrad tutors

best undergrad placement

main reason for $B N$

area of development

career prospects excellent

TOTAL
No. of responses

1

1

2

1

1

2

1

2

1

4

1

1

1

1

1

3

1

1

26

The area of 'self-satisfaction' was clearly the most common reason given with $43.3 \%$ of participants' answers interpreted as fitting within this criteria as in table 2(ii).

\section{2.ii. Self-satisfaction}

\section{Reasons given}

challenging

hope

enjoy staff and patients

enjoy the work/psyche

help others

drawn to $\mathrm{MH}$

passionate about $\mathrm{MH}$

help to empower

utilising self to therapeutically benefit others

interest

fascinating

personally fulfilling

appealing

fascination with human behaviour

good at it

empathy

deal with vulnerable people

excited

society has limited understanding

make a difference in peoples lives
No. of responses

8

1

2

16

3

1

12

1

2

10

3

1

2

2

3

2

1

1

1

3 
enjoy work in community $\mathrm{MH}$

autonomy 1

affinity 2

quality care $\quad 2$

want to be In $\mathrm{MH}$

like 1:1 with people $\quad 2$

rewarding 2

toward recovery $\quad 1$

TOTAL 91

The next most common reason was categorised as 'specific skills' with $21.19 \%$ of participants answering with these responses in table 2(iii).

\section{2.iii. Specific Skills}

\section{Reasons given}

opportunity to educate client and whanau

ability to care for people

communication

work on own

partnership emphasis

people oriented focus

specialised skills and learning required

development of therapeutic relationships

close family focus

interaction with people

self as a tool

personal development interpersonal growth

links to med/diabetes/community/other areas

apply counselling skills

assessment skills helpful in life

self-awareness

easy access to people

prevent acute symptoms

broaden skills

positive gain for their care

more thought consideration

acknowledge emotional realities

understand theory in $\mathrm{MH}$

if mentally well then better able to cope with phys ills

social skills

mulitple skills

TOTAL

\section{No. of responses}

1

1

3

2

3

4

1

5

3

4

3

1

1

1

1

1

1

1

1

1

1

1

1

1

1

1

46

'Personal' made up $15.2 \%$ of responses as in table 2(iv). Contrary to popular belief that money can be a reason for career choices, only $0.92 \%(\mathrm{~N}=2)$ stated this as a reason to work in mental health. 


\section{2.iv. Personal Needs}

\section{Reasons given}

back/knee injury

personality

age -ruled out heavy nursing

flexibility

fulltime/part time

hours of work

career prospects

suits personality

want to work with Maori

goal to limit stigma

sensitive to sight of blood

goal to work in $\mathrm{MH}$

travel

current area of employment

goal to look after PI people

work load

ensure safe environment culturally

estab therapeutic with Maori

natural ability

increase Maori staff numbers

re-enter nursing after family break

past $\mathrm{MH}$ consumer

money

family

TOTAL
No. of responses

2

2

1

1

1

1

1

1

2

2

1

1

2

2

1

1

1

1

1

1

1

3

2

1

33

The final area that I grouped responses into was 'comparison to general nursing'. This made up $9.21 \%$ of comments as in table 2(v).

\section{2.v. Comparison to general nursing}

\section{Reasons given}

not a handmaiden

ability to be a team member

not a factory job

less use of technical equipment

less horizontal violence

more interesting

more money

nicer setting

more physical

interest in social issues not physical

more holistic

less task oriented

prefer to med

not interested in other areas

no uniform
No. of responses

1

1

1

1

1

1

1

1

1

5

2

1

1

1 


\section{Reasons for choosing the least preferred option}

The least preferred option had been selected by this sample as most commonly elderly, operating theatre, midwifery or intensive care areas of nursing. The reasons were given as: "not interested"; "do not enjoy"; "too difficult"; "too depressing"; "not enough interaction"; "too technical”; "too physical”; "too mundane”; "task-oriented"; "too specialized”; "not competent enough"; "previous bad experience”; "death”; "experience of bullying”; "as a male not suited to midwifery".

\section{Reasons for the ranking given for Intensive Care/Critical Care}

As the previous graphs have shown, the area of nursing in intensive care/critical care is not one of the preferred areas to work for most of this population. This next question requested that reasons be given for ranking this area of nursing. Participants were asked not to answer this if the reason had already been covered in questions five and six. Fewer participants completed this question. The reasons given for the ranking fell into two categories: nursing skills and that of environmental factors.

The answers that could be grouped as related to nursing skills were: "lack of communication with clients"; "task oriented"; "dealing with family" and "emotions similar to mental health"; "excellent for assessment skills”; "extra medical skills required thus not suitable for new graduate"; "less confident to work here”. The environmental factors were cited as: "too stressful"; "high powered nursing"; "use of machines/technology"; "no interest”; "good staffing ratios"; "dislike hospital environment"; "more physically focused"; "too busy”; "lots of responsibility”; "blood, sores, vomit". These answers were both negative and positive reasons for working in this area.

\section{Satisfaction of student placement}

The last question asks participants to rate their student placement in mental health using a 'likert' scale (Sheahan, 1984). This question is added to the original questionnaire from the study replicated. The use of an even number of choices was purposeful to avoid the 
ability of the participants to use average scoring by choosing the middle word choice, as had been altered from the pilot study findings. The majority of participants have scored their experiences as being excellent and have offered substantial comments to validate this choice of rating.

Of the replies, $49.5 \%(\mathrm{~N}=50)$ rated their placement as excellent, $29.7 \%(\mathrm{~N}=30)$ as good, $12.87 \%(\mathrm{~N}=13)$ as satisfactory and $4.95 \%(\mathrm{~N}=5)$ as unsatisfactory. Despite the placements not being the best they could be, the participants have still made the choice to work in mental health. This is not surprising when looking at the reasons that have been stated they chose to work in mental health. There are approximately half the placements that students have rated as excellent. But there are still approximately the same amount that have not been at that standard. This leaves plenty of opportunity for improvement to undergraduate placements. However approximately 92\% have received an adequate placement. That could be interpreted as mental health placements are working.

Of those that stated their placement was unsatisfactory, the comments they added were that they were not supported, no preceptor was allocated, students were not valued, experience was different to what had been expected. All these areas can be addressed simply with a little more organisation, some consideration of others and further preparation by nursing schools.

The areas that were commented on in this section of this question ranged from community, long term, crisis assessment treatment team, acute, alcohol \& drug services, inpatient, older person, forensic, adolescents, early intervention service, youth. This provides a varied mix of placements that have been commented on; some participants were able to choose their placements, others stated they would have liked different placements or more variety.

Of the other comments many stated they had chosen to work in mental health because of their placements. The positive comments included "good preceptors"; "good learning 
opportunities”; “well supported”; “inspirational, knowledgeable, professional staff”; "wide range of experiences"; "holistic care"; "well organised"; "interesting work" and “challenging to values", "no horizontal violence”. The comments concentrated on the quality of the preceptor. Many claimed the preceptor was inspirational, knowledgeable and supportive. Where the preceptor was noted to be 'burnt-out' or 'cynical', the rating of the experience was less favourable.

The statistical test comparing an association between the level of satisfaction of the student placement and the sex of the participant was unable to be tested using chi square due to zero being one of the values in the chart. I looked at using Fisher's exact test but this could not be applied due to this test only working with a two by two table. 


\section{Chapter 5}

\section{Discussion}

In interpreting the results of this research, there is a sense that recruitment in the area to mental health is not as great a problem as I at first suspected. This needs to be viewed in the light that I have used a sample that is inclined towards mental health. My original question asks why do nurses choose to work in mental health in an attempt to address recruitment and retention problems that have been reported worldwide, including New Zealand. My belief is that if we can find what attracts nurses into this area of nursing, we will be able to concentrate on these factors in order to implement further strategies that may assist with these problems.

Recently there has been a greater demand to enrol in the CTA funded course from which I have drawn the participants for this survey and I am aware that there was a waiting list for employment in the area I work through this course last year. Perhaps this is the start of an increase in interest in working in mental health. We need to sustain this interest and ensure we retain the nurses that graduate from this course.

By replication of Happell's (1999) study using a sample with some similar characteristics, we have been able to extend Happell's study. The group I have surveyed are those that had continued from their undergraduate nurse education to their first year as a registered nurse. This group has the benefit of reviewing their decision of wanting to work in mental health and looking back at their undergraduate education. By choosing this group, I was anticipating that they would be able to reflect on their experiences through responding to this questionnaire. 


\section{Demographics}

When looking at the demographics of the sample I have chosen to survey, the greater age range does have implications for the future workforce in mental health in that we already have an aging workforce population. The workforce is largely composed of people 35 years and older, i.e. 78\% of mental health nurse workforce in 2003, (National Framework for Mental Health Nursing Draft Discussion Document, 2004). This may result in a sudden decline in mental health nurses as this more mature group reaches retirement age. However the bi-modal distribution from this sample does give the benefit of having a group of younger nurses available as a backstop. This gives a healthy distribution in that we have a young, fresh approach in the first peak as well as a more mature group, possibly parents with families with an assumed "worldly" experience in the second peak. The challenge is to ensure we retain the younger group of nurses in the area of mental health to strengthen numbers for this workforce.

From the results, it is also clear that there are a low number of males attracted to this area of nursing. Approximately $12 \%$ of the sample stated they were males, which was similar to Happell's (1999) study. The total proportion of males of the registered nursing workforce in New Zealand is recorded as 6.4\% (New Zealand Health Workforce Statistics, 2004). As such there is a higher proportion attracted to mental health than other areas of nursing. However there is a great need to increase this proportion to ensure the needs of our male population are met, particularly in the male only areas of mental health and in forensics. This is not diminishing the ability of female registered nurses to care for males, but instead ensuring the availability of gender specific requirements and to have a balanced population of nurses attracted to mental health.

The ethnicity distribution of this population is balanced in this sample, evidenced through this study as at 2005. The statistics from this research show that identified ethnicity is well represented in each area in close relationship to the population distribution in New 
Zealand. This is a beneficial sign that the new graduates to mental health nursing strongly represent the community that they evolve from. This ensures the prospect of cultural awareness and the ability to offer respect to multiple cultures. Cultural awareness makes up an important contribution to nursing practice in New Zealand and for this reason I added the ethnicity question to Happell's questionnaire. From this information, we can assume that initiatives targeting Maori and Pacific Island populations to become registered nurses such as the Ministry of Health scholarships (Mental Health Workforce Development Framework, 2004) are having an impact in 2005. This data will be valuable when looking at future abilities for staff to care for the increasing multiple ethnicities within mental health. However this is limited to only this group of postgraduates, a small percentage of the total mental health workforce.

\section{Results}

In Happell's (1999) study, the focus was placed on the ranking of each of the areas of nursing. The participants were asked to rank the nine areas of nursing according to preference for work. In this replicated study this question was unchanged. The responses were exactly opposite to the results of Happell. This was expected, as the sample group were nurses that wanted to work in mental health. Thus they are termed a biased sample in relation to this question. This study has stated that mental health was first choice for the majority of respondents with community, and elderly areas as next preferred as second choice. These three areas were shown to be the least popular areas in the Australian studies by Happell (1999) and Stevens and Dulhunty (1992). The only area that does not fit with both of these studies is the area of working with children. Working with children was rated as most popular in the two Australian studies and in this study rated within the first, second or third rankings. Working with children also has rated on average as third in the statistical measures in this study. This could be due to the similar attributes required to work in all these areas such as more flexibility, working as a team, importance of communications for caring and family liaison. And perhaps the recent increased interest and growth in the field of child and adolescent mental health may be an added factor, but this is not clear from this research. This however gives evidence that there are similarities 
in each of these groupings and these similarities may be attracted to definite areas of nursing.

Due to the different sample group used to the original study that I have replicated, there are some limitations of comparisons. The sample group have mainly chosen to work in mental health as expected. The surprising finding is that the second choice ranking of other areas to work is community nursing. Perhaps this is due to the assumption that community nursing is mental health community nursing. Or perhaps this is due to the similar characteristics of personalities that are attracted to this area of nursing. Or the similar style of work and skills that are required and that they are both autonomous, nurse led areas, holistic and client centred styles of nursing. Some confusion may have occurred in this study with respondents assuming "community" and "with children” was relating to the mental health classification.

The results however were surprising in that there were thirteen participants who had not chosen mental health as their first preference. From the open-ended questions, this finding may offer some insight into the reasons nurses do not chose mental health as a preferred option. It was clear that for several of these participants, the enrolment into the course was due to employment conditions that they complete this course prior to working in mental health areas. There were two participants that had not been able to get into the general nursing course, so this was an interim choice. Two participants stated they wanted to get mental health experience prior to working in the general side of nursing. This encourages the view that mental health is seen as an integrated part of health care. Several of these participants have stated that they had poor placements but it was obvious from the remarks that this was in relation to their postgraduate experience as well as the undergraduate experience. Two participants stated that they had physical conditions that prevented them working in general nursing areas. 
In the questionnaires open-ended questions that ask 'what reasons have you chosen mental health', the responses have given clear, positive reasons for people to choose to work in this area. The reasons reflect similar themes as in other studies reported in the literature (Moir \& Abraham, 1996, Fergusson \& Hope, 1999). These direct excerpts from the study include the ability to use your self as a therapeutic tool; desire to help vulnerable people; compassion; chance to use communication and interpersonal skills; holistic approach. The implication of these responses is that this is the type of recognition that we should give mental health to the wider community. These are the reasons that drive people to want to work in mental health. These should be the skills that we promote to others and highlight as the attributes of mental health nurses.

These responses were of a positive nature that resounded with a rationalization for the participant's choice of mental health nursing. This was explored by Moir and Abraham (1996) in their study and they concluded these reasons as being justification for a career that was often an unpopular choice. Contrasting mental health with general nursing was a common reason in this study as shown in table 2(v) earlier.

The characteristics such as empathy, interesting, ability to work well in the area, previous experience, rewarding work, challenging, holistic view, ability to work as a team and compassion were similarly found in this research, as did Happell (1999). This leads me to believe that these are the common attributes that nurses associate with the choice to become a nurse. These were not specific to any particular area of nursing. There were however specific positive responses in my study that were more related to mental health nursing such as interest in mental health/psychiatry; therapeutic relationship; working with peoples personalities; ability to use counselling skills; no uniforms; goal to limit stigma associated with mental health.

This study provides evidence that in this particular sample the driver for career choices are reasons of self-satisfaction. The fact that the participants enjoyed the work, gained 
satisfaction, found it challenging, found it more interesting from this area; was more important due to the percentage of participants that stated these comments than any other factors involved in choosing to work in mental health. Happell (1999) discussed the romantic notions that are viewed by nursing students of the more popular areas of nursing. This "romanticism" came through strongly in this categorised area that was labelled "selfsatisfaction" in table 2(ii) in this study. The reasons given offer an altruistic view that provides the degree of self-satisfaction that is clearly important to a career choice for this group of nurses.

From the questionnaire some of the reasons given for the most preferred area to work in are: always been interested in mental health; challenging area to work; personality suited to this type of nursing; and feel comfortable working in mental health. There was an overwhelming response with positive attitudes towards mental health nursing such as “challenging”, “enjoy working in mental health”, "passion”, "interesting”. These were similar findings to Moir and Abraham's study (1996) examining views of students comparing psychiatric and general nursing. A few responses had a recovery approach with a desire to reduce stigma and empower clients in this area.

However it was interesting to compare these results with Happell's groups of undergraduate nurses that ranked other areas higher than mental health. The reasons that were given were often exactly the same, that is: interesting, challenging, I'm good at it, work as part of a team. Due to the same responses being given for all areas of nursing, are we asking the right question? Is it likely that many professions and not just nursing would have similar answers if we repeated these questions to a wider career group?

When the results were analysed, the comments in each of the groupings, were able to identify each group of responses as a percentage. This gives an indication of the most common responses. However most participants gave more than one response that provides the uniqueness of each participant's opinions. This gives evidence to the complex nature 
of the reasons that influence nurses to choose an area to work. Each of these responses has possibly a different meaning to each individual as well.

Each response is important to each individual. The data that has been gathered needs to be used sensitively in the workplace. All of these factors need to be considered when recruiting for new staff and for retaining experienced staff.

In Happell's (1999) study the reasons for not wanting to work in mental health were given as no interest; poor tolerance to the clients; poor understanding of problems; frightening, uncomfortable environment. Happell has not given any of the responses that were positive about mental health nursing, making a comparison of this part of the questionnaire with this study difficult.

The decision to have a career is probably driven by the need to have money. But the decision to choose any specific career is not only driven by money. This is contrary to the notion that an increase in pay rates will encourage recruitment in some areas as often used for bargaining purposes. From this study the responses hinted that money is not the factor that is the greatest influence in people to choose any particular career. It may however assist to retain people in careers. However the questions in this questionnaire were not designed in a way that can substantiate these opinions and it is only through anecdotal evidence that this has any basis.

\section{Attitudes}

The findings from the research that Clarke (1991) completed claiming that there was a significant demonstration that nurses interested in psychiatric nursing were more radical than their general colleagues was not in evidence in the study I have completed. Due to the date that Clarke’s research was completed, what is seen as radicalism in 1991 may not be 
viewed in that way at present. However there may be a need for a more liberal view to be present for nurses to accept people with mental illnesses due to the worldwide marginalisation of this group. Perhaps the nearest radical ideas or comments offered by participants in this study were those that referred to limiting stigma to those that suffer from mental illness.

Both Happell (1999) and Stevens and Dulhunty (1992) have discussed how general community attitudes were reflected through the nursing students opinions. This has been acknowledged within New Zealand and the attempt to destigmatise mental health by the Mental Health Commission (1997) may have an impact or influence on a gradual change in views held by New Zealand society in the future. There were several comments from the participants in this study that reflected that stigma continues through our communities against mental illness. These were in response again to the reason they chose mental health as the most preferred option to work. The reasons suggested that these were personal goals and were worded in this respect: wanting to limit stigma in mental health; society has a limited understanding; and to reduce stigma associated with mental health.

\section{Administration of questionnaire and response rate}

If I had been present when giving out the questionnaires, the response rate may have been higher. I chose not to be present due to the geographical spread of the sample group and the expense that this would have incurred. I could have been present at our local site but this would have produced a bias towards this group and therefore may have skewed the findings. To have a consistent approach I chose to distribute the questionnaire to each of the relevant lecturers.

The study completed by Happell (1999) had a response rate of 93\% and I have assumed that this very high response rate is due to administration of the questionnaire at the 
beginning of the participants' undergraduate experience. Similarly in the study by Stevens and Dulhunty (1992), an even higher response rate of 99\% was achieved and the questionnaire had also been administered at the orientation of their undergraduate course. The contacts at each of the universities rather than the researcher had administered the questionnaire. This early distribution of the questionnaire may have been in an attempt to avoid any influences of studies or student life. It could be argued that this also was a time that the new, eager students would have been heavily influenced to complete the questionnaire by the desire to please their tutors.

On reflection, it would have been preferable if the questionnaires could have been distributed to the sample group on their first day of their course. This would have avoided any misinterpretation of questions such as the questions in relation to placements. This would have been a truer reflection of the participant's undergraduate experiences in mental health.

A group-administered questionnaire generally has a higher response rate compared to a mail out survey, due to the peer pressure of the rest of the group (Gillis \& Jackson, 2002). This was a preferred method to administer the questionnaire to this sample in their nonclinical class time rather than a mail out which would have required several reminders and not such a high return rate. I was able to maintain this method of administration and thus ensured consistency.

A high response rate gives the research more respectability and the ability to generalise about the sample population. To ensure a high response rate, I had offered an incentive of a prize draw to the movies. From the replies, many participants have not completed the slip that asked for the student identification number. This may have been due to the students not having their identification number with them at the time that the questionnaire was offered to them. One lecturer had requested that despite her whole class not having their identification number, they all still wished to go in the draw for the movie passes. For the 
other groups that had returned their questionnaires without completing the entry for the prize draw, I wonder if the reason had been due to them not having access to their student identification number as well. The other factor may have been that the incentive was not of great interest or desirability to many of the participants.

The other factor that determines the response rate is the importance of the topic to the sample group. The use of the information sheet that accompanied the questionnaire is a tool that can influence the participant to complete the questionnaire. The lecturer that was to hand out the questionnaire to the class was sent a letter to explain the research and an instruction sheet was included to give instructions how to administer the tool. I also spoke to each of the lecturers involved and was able to gauge their interest and answer any relevant questions. This enabled some personal control with a likelihood of a positive approach. My response rate of $75.65 \%$ was not as high as the two previous Australian studies using the same tool. This could be attributed to not enough emphasis on the importance of the study in the letters, information sheet and instructions and the importance of timing as stated before. The differing individual approaches by coordinators could have also affected the response rate. However this response rate was pleasing and enabled generalisability of the results.

Following receiving the completed questionnaires from the lecturers, I made a request of information about how many students were offered the questionnaire. On reflection, it would have been more efficient to accompany the package sent to the lecturers with a form to complete requesting this information. 50\% of the lecturers responded to this request, and I have assumed that the original information that I had gathered about the sample had not altered from the lecturers that did not respond. 


\section{Limitations of questionnaire}

The emphasis that Happell put on her study was where nurses want to work. The question I wanted to ask was 'why' instead of 'where'. The question that requested ranking of the areas of nursing was interesting and gave some insight into how nurses place each area of nursing in order of preference to work. It also had some merit in getting the participants to think about the actual time of making a choice to work in mental health; a place to reflect. The questions that gave the most information were the open-ended ones that asked for the reasons. These open-ended questions however are complex in nature and difficult to categorise, thus are influenced heavily by researcher bias. This is a limitation that needs to be kept in focus when discussing the findings (Gillis \& Jackson, 2002).

Despite the use of a pilot of the questionnaire with a small group of colleagues, some of the following limitations had not been highlighted. On reflection, I had not spent enough time with each of the pilot participants to check their understanding of the questions.

Unnecessary questions (Sheahan, 1984) in this questionnaire were limited to the one that requests information about previous nursing experience. This gave little useable data. If there was relevance of previous experience for the reasons for working in mental health this was stated in the open-ended questions. There was also evidence of misinterpretation of what is intended by the terminology 'nursing' in some of the responses.

The large number of choices of areas of nursing that participants were asked to rank in the question number five may have been the reason that many participants did not follow instructions of this part of the questionnaire. Many had chosen only three areas to rank; some had ranked several areas as ' 9 ' or ' 5 '. These responses had lead to them being 
categorised as missing data due to inability to analyse the responses accurately. Perhaps if the question had been limited to only six areas, this may have been more manageable. By altering the question to choosing three areas from the list of nine areas and rate these as first, second or third, could have been another alternative to assist in ease of interpretation.

The areas of nursing may also have been misinterpreted. The community area may have been thought to be 'community mental health' and the 'childrens' area may have been thought of as 'childrens mental health'. This area of ambiguity has lead to potential misinterpretation of directions and mistakes in responding thus have made this question less useful.

From this inability to make clear deductions, the choice of using a questionnaire has highlighted some of its limitations. From this probable misinterpretation, I wanted to ask the participants further questions to clarify their choices. This was a disadvantage of using the questionnaire that I could not go back to the participants for this clarification.

Questionnaires that are distributed by other than the researcher have some limitations (Gillis \& Jackson, 2002). Despite having the researchers phone number available for any queries about the questionnaire, it may have been advantageous to be present at the time the questionnaires were given out. However this may create researcher bias from the answers the researcher may give to the participants. From the viewpoint of the researcher however, several times during the analysis of data, it would have been helpful to have a dialogue with the participant to check their understanding of the questions. This was identified with some of the answers not corresponding to the questions. I wondered whether the question had been misinterpreted.

The other disadvantage is that we are relying on the memory of the participants as to the reason they decided to work in mental health as well as the other open-ended questions. 
Relying on retrospective recall may lead to possible inaccuracy of memory (Sheahan, 1984). But on the other hand this time lapse may allow further valuable reflection on their opinions and decisions.

\section{Reliability}

The decision as to how reliable this tool is to measure the research question in this study may however be questioned. The studies by Happell (1999) and Stevens and Dulhunty (1992), can be confirmed that there is a degree of reliability and validity for the questions they were asking. Reliability of this survey tool has been assessed as being strong due to similar results when used on similar samples. There were consistent findings following each use of the tool in the pilot studies prior to each administration and the successful administration on three occasions. They appeared to measure what they were designed to measure however no test approach had been used.

In surveys it can be difficult to measure validity due to opinions and attitudes being reported (LoBiondo-Wood, \& Haber, 1994). In any questionnaire we cannot be sure that the answer that is given by the participant is actually how they behave or think in reality. It is this reliability that may be difficult to measure. The reliability of the tool to be used on this sample group has created issues in that this group are assumed to have already chosen their career, whereas in the earlier studies the sample were in their prime of deciding on a choice of career. Therefore the tool really is not as effective at giving an answer to the question we want to ask - that of why choose mental health. Despite not establishing reliability or validity of this questionnaire, the responses from the participants remain valuable.

The questionnaire was distributed to a nationally spread group of nurses. This enabled the opinions to include the diversity of experiences in all regions of New Zealand. This allows 
the study a degree of generalisability especially as the findings are similar to those found in literature internationally. However the opinions need to be viewed in perspective that this is a small proportion of the entire mental health nursing population of New Zealand, thus requiring some caution with broad conclusions.

\section{Student placement}

The idea that student placement has an influence over the choice of future career choices was tested with the final open-ended question. This question was added to the original questionnaire due to my personal research positioning. The question firstly asks for a rating of the participants' undergraduate placements in mental health. It gives a choice of excellent/good /satisfactory /unsatisfactory and requests the participant to circle one rating. Then it provides a space for any comments about this/these placements. During the pilot study it was found that participants were more likely to choose the middle value of the scale hence the use of even amounts of choices were provided for a more balanced, accurate result. Exposure to a positive clinical placement was cited as a reason for many of the participants in this study to choose mental health as an area to work. The positive aspects included in the responses were: a welcoming response to students by staff; professional attitude and knowledge of staff; ability to have a variety of experiences while in placement; and enjoyment of the placement. This is similar to findings by Perese (1996) and Clarke (1991).

From my clinical experience, the nurses that are involved in preceptoring nurses in these placements require positive feedback in the form of some type of reward so as to recognise the value of their input. While preceptoring, the nurse needs to have a lower case load in order to spend more time with the undergraduate. The preceptors need extra guidance as to how students learn and how to adapt the text book learning that comes from the educational institutes into a form that is able to marry clinical practice to this model. Some of the more negative comments in this study were written related to identifying "burnt out" 
staff, negative staff attitudes, lack of support for students, poor emphasis during undergraduate programme, not long enough in each placement, and horizontal violence (only one mention). This compares similarly to the study completed by Perese (1996) in New York with undergraduates commenting on their mental health placements where they rated the positive and the negative aspects. Positive (as explained by Perese) being feeling welcomed and supported by staff; opportunities for direct and active involvement by clients; opportunities for rich and diverse learning; interaction with staff who are professional and enthusiastic about their clinical field. The negative comments were their perceived lack of confidence knowledge and skills to the challenges during their experiences in mental health.

This highlights how each experience will be different depending on many variables such as the extent and quality of the preceptorship, what experiences are available, previous life experiences, and attitudes of both the preceptor and the student. The overall impression from the comments given in this study was that the placement had made a difference to the choice of career. These findings are similar to what Nolan and Chung (1998) found in their United Kingdom (UK) study of students’ first impressions of mental health placement finding there was a significant shift in attitudes following placement. Fergusson and Hope (1999) in their UK longitudinal study, also agreed that there is a need for exposure to practice in order for undergraduates to make decisions as to career choice.

The assumption that nurses have chosen to work in the area of mental health due to their student experiences appears to be a large factor in this decision. I am convinced that this is the area we need to concentrate on in order to address our recruitment issues. Both the comments from the participants about their student placements and anecdotal evidence from the undergraduate students that I have worked with argue that placements can influence future decisions about career choices. In my experience, many students have come to mental health in an anxious, cautious, negative state and regularly complete their practicum with statements such as "I never thought that I would consider working in mental health”. With organisation, available valuable experiences and specific supports in place, we as nurses can make a difference at these practicums to attitudes that have been coloured by society. 
The other reasons for choosing to work in mental health may be linked to different personality types, having different interests and drivers for career decisions. These are recognised by the literature but have not been described as a significant proportion in this research.

Another area that would provide extra information about retention of staff would be the reasons nurses leave their mental health workplaces. This has not been explored in this study but if all staff were required to complete an exit interview, this information could assist with future research.

\section{Knowledge gained}

Throughout the process of this research, I have extended my learning in many ways. I have been able to develop my academic writing to the acceptable level for a thesis. In order to commence this study, I needed to identify a topic that would sustain my interest over the duration of the project and ensure the topic was of sufficient importance that could add valuable data to nursing, yet could be simplified to a narrow field of the topic. These aspects have meant that I had to give much thought and seek advice from colleagues. Once the topic had been decided, the ethical implications of this study had to be considered. The process of gaining ethical approval was able to show me the depth of thought that is given to research projects and how the guidelines have ensured safety in multiple ways to protect the intended participants.

The use of a questionnaire has highlighted to me how important the questions are to the topic being researched. Their relevance to the topic will direct how the responses will be open for analysis. Modification of the tool that I used, as mentioned previously, could 
have extended this research to allow a closer link to the thesis question. Throughout the study I have gained understanding of the contextual differences between the replicate study and my own.

By completing analysis of data I have needed to learn new skills such as use of spreadsheets and how to categorise data. The categorising of the open-ended questions has required that I give extensive thought to the responses given and how these could be grouped. Interpreting of the responses was a complex issue and the conclusions that I have drawn from these were limited to my perception only. This aspect has made me very aware of viewing other people's research with a critical regard to how the researcher has positioned themselves and as to how the findings could be interpreted in different ways.

On reflection, the problems that I have come up against have made me recognise the importance of organisation and the discipline with time keeping. The feedback and guidance that has been offered to me by supervisors and colleagues has made me appreciate and listen to their advice. The final conclusions to the study have been influenced heavily by the literature that I have reviewed. However, restricting the study conclusions to those that have been informed by the questionnaires data has been the greater challenge. The research data has allowed analysis that provides more questions to be asked and more opportunities for continuing research in this area.

The findings from this study will be summarised and made available to the participants of the survey. The results will be submitted for publication in a mental health nursing journal. 


\section{Chapter 6}

\section{Conclusion}

This study set to examine the reasons nurses choose to work in mental health. Many factors will influence this decision and not all of these influences have been represented by the participants as responses in this study. The questionnaire is able to describe the reasons but is probably not able to explain them. Some of these influences may need more time and reflection and the use of face-to-face interviews or focus groups may extract these other influences more readily in future studies to gain this explanation. I do not expect to get a definitive answer from this research, as choice of a career is a very complex activity. As the evidence from the data in this study has shown, there are many differing reasons people choose to work in mental health. This study has opened up many more questions.

The results of this study have many similarities to those that have been reviewed through the literature. This provides evidence that experiences of undergraduate nurses throughout the world show some resemblance. The reasons given for wanting to work in mental health are surprisingly similar to the reasons nurses want to work in other areas of nursing. This asks the question further, are these reasons peculiar to only nursing or are these the reasons that people make any career choice?

Part of the study has told us why nurses choose to work in mental health if they are enrolled in the postgraduate programme. This study also tells us where nurses want to nurse. To broaden these questions further research needs to ask undergraduates these same questions. Modification to the tool for easier use of the ranking scale would be an 
advantage and perhaps reducing the number of questions that are asked to the specific questions that have provided the most valuable answers.

The use of the survey for this study was appropriate. However to extend the study further, a qualitative research design with in-depth interviews or focus groups will draw out data that would be able to be interpreted with greater reliability and with a richness of responses. This type of research enables the researcher to ask questions to clarify viewpoints from the respondents, something that the questionnaire is unable to do.

Due to there being a scarcity of research around this topic in New Zealand, further studies surrounding recruitment and retention strategies are required. An area that has not been discussed is the reason nurses choose to leave mental health. Or the reasons nurses chose to work in general nursing areas compared with working in mental health. These would provide more valuable data for future research.

We also need to continue to question our student placements in mental health and whether we need to modify our practices. The success of the student placements is reflected in the proportion of nurses wishing to return to mental health following their graduation. There are many influences involved in nurses making choices to work in the area of mental health and these have been outlined in this study. Some of these we have no control over, such as personality type and attitudes (Clarke, 1991), previous life experiences, "feelings that we are good at this type of nursing", "positive feelings when we work in this area" "passion and fascination for mental health" as verbatim responses from the questionnaire.

Others we do have some control over. These are the influences that are produced from the student placements we experience in mental health "rewarding”, "enhanced my practice”, "well-supported and welcoming for students" as further responses from the questionnaire evidence. The emphasis and prominence that is given during undergraduate nursing 
courses has also the ability to be controlled in order to encourage more nurses to consider working in mental health.

If we are to continue to specialise nursing at an undergraduate level then we will need to put a greater emphasis on mental health in pre-enrolment situations such as high schools, career opportunities, employment websites as Wells, McElwee and Ryan (2000) concluded. We need to make nursing in areas of mental health more attractive.

From these findings, I recommend that more emphasis be placed on the mental health practicum component of the undergraduate-nursing course. I believe that the comprehensive nursing course that is at present in place throughout New Zealand has the correct positioning for further development. The idea of streaming specialised areas of nursing that have been discussed anecdotally is likely to continue to reduce recruitment to these areas due to the reduced exposure by those that hold negative perceptions of mental health. We need to expand the experiences of all nursing students and view mental health as part of the holistic approach. The importance of mental health needs to be seen in this perspective so as to diminish the fears and stigma that society holds.

With the increase in primary health initiatives, mental health will continue to have an increased need for a larger, stronger mental health workforce. By adopting undergraduate programmes that specialise from foundation courses we run the risk that less people will be attracted to mental health due to this decreased exposure and this will reduce the available workforce numbers considerably. The CTA funded entry to practice programmes is in response to the need to enhance the practice of new graduates. Continued discussion needs to take place with educators and clinicians to put in place strategies that will continue to lift the status of mental health nurses. 
From the responses given in this study, we should take pride in the reasons that nurses have chosen to work in mental health. Such answers as more holistic view; more autonomy; personally fulfilling; fosters personal growth; less task oriented; New Zealand's progressive approach in mental health; more respected as a profession; use of self as a therapeutic tool; can a make a difference in somebody's crisis; are all answers that we can place a high value of ourselves. These are the types of statements we need to make well known to the community we work within and promote our skills. Nurses are the best people to take on this entrepreneurial task and ensure our consumers are aware of our ability to provide care for their mental health needs. In turn this could lead to creating a culture that will value the area of mental health nursing. 


\section{References}

Abdellah, F. \& Levine, E. (1986). Better patient care through nursing research. ( ${ }^{\text {rd }}$ Ed.). New York: Macmillan.

Aiken, L., Havens, D. \& Sloane, D. (2000). The magnet nursing services recognition program: a comparison of two groups of magnet hospitals. American Journal of Nursing, 100(3), 26-36.

Benner, P. (1984). From novice to expert. Menlo Park, California: Addison-Wesley.

Campbell, M. (1971). Study of the attitudes of nursing personnel towards geriatric patients. Nursing Research, 20, 147-151.

Caroselli-Karinja, M., McGowan, J. \& Penn, S. (1988). Internship programs are safeguarding the future of psychiatric nursing. Journal of Psychosocial Nursing, 26, 28-31.

Clarke, L. (1991). Attitudes and interests of students and applications from two branches of the British nursing profession. Journal of Advanced Nursing, 16, 213-223.

Clinton, M. \& Hazelton, M. (2000). Scoping the prospects of Australian mental health nursing. Australian and New Zealand Journal of Mental Health Nursing, 9, 159165.

Durkin, A. (2002). Psychiatric nursing recruitment: roles for educators and nursing staff. Journal of Psychosocial Nursing and Mental Health Services, 40(8), 32-36.

Ellis, P. \& Collings, S. (Eds.) (1997). Mental health in New Zealand from a public health perspective. Wellington: Ministry of Health.

Farrell, G. \& Carr, J. (1996). Who cares for the mentally ill? Theory and practice hours with a 'mental illness' focus in nursing curricula in Australian universities. Australian and New Zealand Journal of Mental Health Nursing, 5, 77-83.

Ferguson, K. \& Hope, K. (1999). From novice to competent practitioner: A longitudinal study tracking the progress of undergraduate mental health nursing students. Journal of Advanced Nursing, 29(3), 630-638. 
Gillis, A., \& Jackson, W. (2002). Research for nurses: methods and interpretation. Philadelphia: F.A. Davis Company.

Happell, B. (1999). When I grow up I want to be a...? Where undergraduate student nurses want to work after graduation. Journal of Advanced Nursing, 29(2), 499-505.

Happell, B. \& Rushworth, L. (2000). 'Psychiatric nursing was great, but I want to be a “real” nurse': Is psychiatric nursing a realistic choice for nursing students? Australian and New Zealand Journal of Mental Health Nursing, 9, 128-137.

Happell, B. (2001). Comprehensive nursing education in Victoria: rhetoric or reality? Journal of Psychiatric and Mental Health Nursing, 8, 507-516.

King, M. (2002). Being pa'alangi. Retrieved 2 January 2006 from http://www.futurestrust.org.nz/Michael\%20King\%20Tribute.pdf

Kramer, M. (1983). The increasing prevalence of mental disorders: A pandemic threat. Psychiatric Quarterly, 55, 115-143.

Lo, R. \& Brown, R. (1999). The importance of theory in student nurses' psychiatric practicum. International Journal of Psychiatric Nursing Research, 5(1), 542-552.

LoBiondo-Wood, G. \& Haber, J. (1994). Nursing research. Methods, Critical Appraisal, and Utilization, ( ${ }^{\text {rd }}$ Ed.). St. Louis: Mosby.

Mendelson, G. (2003). Magnet recognition attracts and retains the very best - and not just nurses - hospitals achieve quality status, higher patient satisfaction. Maryland Nurse, 5(2), 7-8.

Mental Health Commission. (1997). Blueprint for mental health services in New Zealand: working document 1997. Wellington: Mental Health Commission.

Mental Health Workforce Development Framework, 2004. Context of mental health workforce development initiatives. Wellington: Ministry of Health.

Moir, J. \& Abraham, C. (1996). Why I want to be a psychiatric nurse: constructing an identity through contrasts with general nursing. Journal of Advanced Nursing, 23, 295-298.

Mullen, A. \& Murray, L. (2002). Clinical placements in mental health: are clinicians doing enough for undergraduate nursing students? International Journal of Mental Health Nursing, 11, 61-68.

Munro, B. (2005). Statistical methods for health care research, (5 ${ }^{\text {th }}$ Ed.). Philadelphia: Lippincott.

Murrells, T. \& Robinson, S. (1998). Researching career plans and career histories of mental health nurses. International Journal of Nursing Studies, 35, 233-242. 
National framework for mental health nursing draft discussion document, (2004). Wellington: Expert Reference Group.

New Zealand Health Workforce Statistics, 2004. Retrieved 2 January, 2006, from http://www.nzhis.govt.nz/stats/nursestats.html.

Nolan, P. \& Chung, M. (1999). Nursing students’ perceptions of their first mental health placement. Nurse Education Today, 19, 122-128.

Nursing Council of New Zealand Code of Conduct. Retrieved 10 December, 2005, from http://www.nursingcouncil.org.nz/Publications/

O'Donnell, H. (2003). The future of mental health nursing in Northern Ireland: does anyone really care? Mental Health Practice, 7(3), 30-33.

Peplau, H. (1989). Future directions in psychiatric nursing from the perspective of history. Journal of Psychosocial Nursing, 27, 18-28.

Perese, E. (1996). Undergraduates' perceptions of their psychiatric practicum: positive and negative factors in inpatient and community experience. Journal of Nursing Education, 35(6), 281-285.

Polit, D., Beck, C. \& Hungler, B. (2001). Essentials of nursing research: methods, appraisal, and utilization, ( $5^{\text {th }}$ Ed.). Philadelphia: Lippincott.

Prebble, K. \& McDonald, B. (1997). Adaptation to the mental health setting: The lived experience of comprehensive nurse graduates. Australian and New Zealand Journal of Mental Health Nursing, 6,30-36.

Prebble, K. (2001). On the brink of change? Implications of the review of undergraduate education in New Zealand for mental health nursing. Australian New Zealand Journal of Mental Health Nursing, 10(3), 136-144.

Rungapadiachy, D., Madill, A., \& Gough, B. (2004). Mental health student nurses' perception of the role of the mental health nurse. Journal of Psychiatric and Mental Health Nursing, 11, 714-724.

Sheahan, J. (1984). Surveys, questionnaires. In Cormack, D. (Ed.) The research process in nursing. Oxford: Blackwell Scientific Publications.

Statistics New Zealand (n.d.). Census of population and dwellings. Retrieved 27 November, 2005, from http://www2.stats.govt.nz/census2001.htm.

Stevens, J. \& Crouch, M. (1995). Who cares about care in nursing education? International Journal of Nursing Studies, 32(3), 233-242.

Stevens, J. \& Dulhunty, G. (1992). New South Wales nursing students' attitudes towards a career in mental health. Australian Journal of Mental Health Nursing, 2(2), 59-64. 
Stevens, J. \& Dulhunty, G. (1994). Nurse education does not produce mental health nurses: curricula in need of new direction. Proceedings, Australian and New Zealand College of Mental Health Nurses, $20^{\text {th }}$ Annual convention, October, Brisbane.

Taylor, B. \& Barling, J. (2004). Identifying sources and effects of carer fatigue and burnout for mental health nurses: a qualitative approach. International Journal of Mental Health Nursing, 13, 117-125.

The Declaration of Helsinki (1965), retrieved 10 December 2005 from http://www.wma.net/e/policy/b3.htm

Wells, J., McElwee, C. \& Ryan, D. (2000). 'I don’t want to be a psychiatric nurse': An exploration of factors inhibiting recruitment to psychiatric nursing in Ireland. Journal of Psychiatric and Mental Health Nursing, 7, 79-87.

World Health Organisation. (2004). Mental Health. Retrieved 19 September, 2004, from http://www.who.int/mental_health/en/

Wynaden, D., Orb, A., McGowan, S., \& Downie, J. (2000). Are universities preparing nurses to meet the challenges posed by the Australian mental health care system? Australian New Zealand Mental Health Nursing, 9(3), 138-146. 